\title{
EL CONSEJO DE ESTADO GADITANO ${ }^{1}$
}

\section{THE COUNCIL OF STATE OF CADIZ}

\author{
Sara Moreno Tejada \\ Universidad Miguel Hernández
}

\begin{abstract}
SUMARIO: I. INTRODUCCIÓN.- II. EL CONSEJO DE ESTADO EN LAS CORTES DE CÁDIZ.- 2.1. Sobre la conveniencia de la Administración consultiva.- 2.2. El debate sobre la composición del Consejo de Estado.- 2.3. En torno a las competencias del superior Cuerpo consultivo.- III. EL RESTABLECIMIENTO DEL CONSEJO GADITANO.- IV. EL CONSEJO DE ESTADO DURANTE LA REGENCIA DE MARÍA CRISTINA.- V. CONCLUSIONES.
\end{abstract}

Resumen: El primer Consejo de Estado Constitucional fue instalado por las Cortes de Cádiz al considerar que su existencia era totalmente imprescindible en el régimen que se trataba de instaurar. Esta concepción, que se mantuvo en 1820, desapareció tras la década ominosa. De esta forma, durante la Regencia de Maria Cristina ya no sería considerado un órgano esencial que debía estar necesariamente contemplado en la norma fundamental. Este trabajo está destinado a examinar los debates parlamentarios y la doctrina administrativa para desentramar los fundamentos en que se basaban las distintas consideraciones que sobre ésta Corporación recayeron en tan breve periodo de tiempo.

Abstract: The first Constitutional Council of State was installed by the Parliament of Cádiz in considering that its existence was absolutely imperative to the regime that was sought to establish. This conception, that was maintained throughout 1820, disappeared after the ominous decade. During the regency of Queen Maria Cristina this Institution would no longer be considered as an essential organization that should necessarily be contemplated in the Constitution. This work is intended to study the parliamentary debates and the administrative doctrine in order to find out the different considerations relating to this Corporation.

Palabras clave: Consejo de Estado, Siglo XIX, Constitucionalismo, Doctrina administrativa, Debates Parlamentarios.

Key Words: Council of State, nineteenth century, Constitutionalism, Administrative doctrine, parliamentary debates.

\section{INTRODUCCIÓN}

El Consejo de Estado es una de las escasas instituciones que ha sobrevivido, con entereza, a los diferentes embistes causados por las luchas de partido y los cambios de régimen sufridos en España a lo largo de los dos últimos siglos.

1 Este artículo se ha escrito en marco del proyecto de investigación El Consejo de Estado en el Trienio Liberal DER 2014-58874-P MINECO 
Actualmente, no existe duda, se encuentra firmemente afincado en nuestro ordenamiento jurídico; concretamente, en el artículo 107 de la Constitución, que lo define como "(...) el supremo órgano consultivo del Gobierno". Si investigamos sus origenes, encontraremos que es descendiente del instaurado por las Cortes de Cádiz en 1812. Las raíces de este último, por contra, no son tan claras ${ }^{2}$.

Es indudable que desde los albores de la monarquía ha sido necesaria la existencia de un conjunto de expertos encargados de asesorar al Ejecutivo en los asuntos más complejos y relevantes de gobierno. A modo de ejemplo cabe citar el texto de Tácito, el Germania, hacia el año 100, en el que habla del consilium, o los Fueros de Nájera o Sahagún, en los que se vuelve a mencionar a la misma Institución constituida por los prelados y magnates a los que el monarca consultaba en los negocios primordiales ${ }^{3}$. Así, de forma lenta y continuada, se fue creando esta Corporación que, fuertemente arraigada, se convertiría en una pieza fundamental de la Administración. Sin embargo, siguiendo a Colmeiro, no se configuró como un órgano permanente y provisto de funciones propias hasta 1385, cuando el rey Juan I decretó la instauración del que, a partir de ese momento, se denominaría "Consejo Real y Supremo de Castilla"4. Tras importantes modificaciones en su composición a lo largo de los distintos reinados que se fueron sucediendo, los Reyes Católicos fijaron en doce el número de consejeros, entre los que preponderaban los letrados, causa ésta, según el referido estudioso, de que incrementase su prestigio, conociendo de la mayor parte de los asuntos del reino y dotándosele además de jurisdicción propia ${ }^{5}$. A partir de este momento fue fortaleciéndose y ensanchando sus atribuciones, hasta que con la llegada de los Borbones, y la creación de las distintas Secretarias de Estado, comenzó el principio de su decadencia, aun cuando

2 Un examen detenido de esta importante cuestión lo encontramos en Feliciano Barrios Pintado, El Consejo de Estado de la Monarquía Española 1521-1812, Instituto de Estudios Politicos, Madrid, 1944; José $\mathrm{M}^{\mathrm{a}}$ Cordero Torres El Consejo de Estado. Su trayectoria y perspectivas, Instituto de Estudios Políticos, Madrid, 1944; Santos Mª Coronas González, "La crisis del Antiguo Régimen consultivo en la España constitucional”, Revista de Estudios políticos, $\mathrm{n}^{\circ}$ 57, 1987, pp. 177-190; Luis Jordana de Pozas, El Consejo de Estado español y las influencias francesas a lo largo de su evolución, Consejo de Estado, Madrid, 1953; o José María Martín Oviedo, El Consejo de Estado durante el régimen constitucional (1808-1812), Madrid, 2012. También en la doctrina contemporánea, entre ellos: Manuel Colmeiro y Penido, Derecho Administrativo Español, Madrid, 1850, pp. 176 y ss.; Fernando Cos-Gayon, Historia de la Administración Pública de España en sus diferentes Ramos de Derecho político, Diplomacia, Organizacion Administrativa y Hacienda, desde la dominacion romana hasta nuestros dias, Madrid, 1851, pp. 213 y ss; o José de Posada Herrera, Lecciones de Administración, Tomo I, Madrid, 1843, p. 307 y ss.

3 Teresa María Navarro Caballero, "El Consejo de Estado. Orígen Histórico y Regulación actual a la luz de la Ley Orgánica 3/2004 de 28 de diciembre”, Anales de Derecho, n 24, 2006, p. 11.

4 Manuel Colmeiro y Penido, Derecho Administrativo Español, op.cit., p. 177. Llega a la misma conclusión José de Posada Herrera al afirmar que: "No se sabe a punto fijo cuando ha nacido en España el consejo de estado. Se le encuentra en el principio de la monarquía pero no se le puede dar época determinada. (...) D. Juan I (...) en las Cortes de Valladolid de 1358 consintió en la creacion de un Consejo, compuesto de cuatro prelados, cuatro caballeros y cuatro ciudadanos, y aumentó despues sus atribuciones en las cortes de Bribiesca de 1837(...)", José de Posada Herrera, Lecciones de Administración, op.cit., p. 307.

5 Manuel Colmeiro y Penido, Derecho Administrativo Español, op. cit, p. 178. 
todavía perdurase casi un siglo $^{6}$ y se intentase revitalizar por el Conde de Aranda bajo el reinado de Carlos IV7. Una vez entrados en el siglo XIX, fue suprimido por las Cortes de Cádiz el 26 de enero de 1812, que siendo conscientes de la necesaria reforma de la Administración española, como se desprende de la propia Constitución ${ }^{8}$, sin pérdida de tiempo, e incluso antes de aprobar la Carta Magna, se encargaron de instaurar un nuevo órgano superior consultivo acorde con el nuevo régimen.

De lo hasta aquí manifestado obtenemos una rápida conclusión y es que, de acuerdo con Cordero Torres, si bien no es posible reconocer al Consejo de Estado gaditano unos padres muy longevos -pues no es en modo alguno comparable con la Institución preconstitucional-, sí es factible atribuirle unos antepasados lejanos ${ }^{9}$.

Hasta el momento, gran parte de la historiografia ha dirigido sus esfuerzos al estudio de la normativa reguladora de esta Corporación. Es, sin duda, una tarea imprescindible para el conocimiento de la misma, pero ha de ser necesariamente completada por el análisis de su actividad ${ }^{10}$ y el examen de los Diarios de Sesiones de Cortes, la opinión pública y la doctrina, que nos facilitan la comprensión del pensamiento reinante en el momento. Ésta última cuestión es a la que hemos dedicado las sucesivas líneas. En este sentido, hemos espigado los debates que tuvieron lugar en las Cámaras legislativas de 1812, 1820 y 1837, en los que se discutió acerca de la conveniencia de este Cuerpo consultivo, y también sobre su configuración y competencias. De la misma forma, se ha prestado atención a la prensa y a las obras de algunos de los grandes administrativistas del momento. El objetivo de este trabajo consiste, por un lado, en dilucidar los argumentos que utilizaron los diputados para establecer una entidad que, si bien con ánimo de ser totalmente renovada, hundia sus raíces en el régimen al que trataban de poner fin; y, por otro, pergeñar los motivos del cambio de pensamiento en relación a la necesaria existencia de este ente superior de la Administración.

\section{EL CONSEJO DE ESTADO EN LAS CORTES DE CÁDIZ}

España entró en el siglo XIX con una gran crisis monárquica que inició con el Motín de Aranjuez y culminó con las abdicaciones de Bayona11. Esta

${ }^{6}$ Luis Jordana de Pozas, El Consejo de Estado español y las influencias francesas a lo largo de su evolución, op. cit., p. 16.

${ }^{7}$ Feliciano Barrios Pintado El Consejo de Estado de la Monarquía Española 1521-1812, op. cit., p. 193.

8 Francisco Javier Sanjuán Andrés, "Las Diputaciones Provinciales. Una aproximación a los origenes de la Diputación de Cádiz”, Historia Constitucional, n 13, 2012, p. 2.

9 José $\mathrm{M}^{a}$ Cordero Torres, El Consejo de Estado. Su trayectoria y perspectivas en España, op. cit., p.21.

10 En este sentido, es de justicia citar los trabajos de Ricardo Gómez Rivero, excelente conocedor de la materia. En sus obras Consejo de Estado y Regencia del Reino (1812-1814) y El Primer Consejo de Estado Constitucional, 1812-1814, realiza un completo examen de sus sesiones, actas y expedientes relativas a los asuntos de Gracia y Justicia, Estado, Guerra, Hacienda y Marina.

${ }_{11}$ Miguel Artola, La España de Fernando VII, Espasa Calpe, 1999, p. 67. 
importante depresión implicó la quiebra de los órganos de gobierno existentes en el absolutismo, sustituyéndose las viejas instituciones por otras nuevas o adaptando las ya existentes al naciente régimen constitucional ${ }^{12}$. En esta coyuntura se encuadra el Consejo de Estado, que se creó por el decreto CXXIV, firmado en Cádiz el 21 de enero de $1812^{13}$. En dicha norma se reflejaba el acuerdo de las Cortes por el que habian decidido, una vez nombradas las personas que habian de componer la Regencia:

“(...) elegir por sí mismas por esta vez 20 individuos para el citado Consejo de Estado, de los cuales, seis á lo menos serán naturales de las provincias de Ultramar; y de todo el número dos eclesiásticos, y no más, uno de ellos Obispo, y el otro constituido en dignidad; dos grandes de España y no más, y los restantes serán elegidos de los sugetos que sirvan ó hayan servido en las carreras diplomática, militar, económica y de magistratura, y que se han distinguido por su talento, instruccion y servicios"14.

Es de destacar la gran celeridad con que los diputados procedieron a la creación de este Cuerpo consultivo ${ }^{15}$. Tal era el apremio, que el nombramiento de

12 En estos términos se expresaba, en concreto, el redactor del diario "El Revisor Politico" asegurando que el levantamiento contra la invasión napoleónica había producido el indiscutible beneficio de obligar a la reorganización de la Administración pública española, hasta el momento envuelta en el desorden y camino de la decadencia. Decía: "Hemos dicho varias veces que uno de los mayores males que hemos sufrido en nuestra revolución y que hasta cierto punto era indispensable, ha sido el carecer de sistema en los diversos ramos de la administracion pública. Increible parecía que tan facilmente se hubiesen conformado las voluntades para el establecimiento de la Junta Central: qualesquiera que hayan sido los defectos de aquel gobierno, siempre la España diò un gran paso reuniendo el exercicio de la autoridad y la soberania en un solo cuerpo y destruyendo asi todas las causas que pudieran habernos llevado á la anarquia, ó quando menos al federalismo con perjuicio de nuestras instituciones y de nuestros intereses politicos con las demas Potencias. (...) La Europa habia visto que el desorden de nuestra antigua administracion, el olvido de nuestros fueros y nuestras leyes y la privanza de un Valido insensato, habian degradado la nobleza del caracter castellano y que el formidable imperio de un Cárlos V habia llegado à ser el objeto de la mofa y del desprecio. Habria sido una ignorancia imperdonable no aprovechar la oportunidad que se nos ofrecia para resucitar nuestra perdida libertad y fixar clara y sistematicamente nuestras futuras instituciones. Los reyes y los pueblos tienen un interès en esto: y solo una mal entendida fidelidad puede encontrar injustas estas disposiciones. (...) Las mudanzas de gobierno que hemos experimentado y los males que hemos padecido succesivamente no han impedido sin embargo la conclusion de la Constitucion, la formacion de la nueva Regencia, la creacion del Consejo de Estado y la consolidacion de unos principios muy arreglados á la razon y la justicia. (...)”. El Revisor Politico, n 62 , sábado, 8 de febrero de 1812 , p. 261 .

13 Cinco días más tarde sería suprimido el Consejo de Estado absolutista por Decreto CXXX, de 26 de enero de 1812. Esta disposición se puede encontrar en Documentos del Reinado de Fernando VII. VII. El Consejo de Estado (1792-1834), Ediciones de la Universidad de Navarra, S.A., Instituto de Estudios Administrativos, 1971, p. 116.

14 Decreto CXXIV de 21 de enero de 1812.

15 Esta urgencia es patente en los Diarios de Sesones de Cortes, concretamente en el de 31 de octubre de 1811, cuando García Herreros mostró su preocupación ante la necesidad de que los consejeros de Estado fuesen elegidos, de acuerdo con el artículo 233, por el monarca, que se hallaba ausente. Esto significaba la posibilidad de que dicha elección se pudiese diferir en el tiempo y, en ese caso, "protestaba dicho artículo, y ofrecía presentar una adicion (...)". Le contestó Argüelles que este problema ya estaba solventado, pues el artículo 195 autorizaba a las Córtes para conceder a la Regencia las facultades del Rey en los términos que estimasen conveniente, Diario de Sesiones de las Cortes (en adelante DSC), 31.10.1811, nº 394, p. 2186. 
sus miembros se produjo el 19 de febrero ${ }^{16}$, un mes antes de la promulgación de la propia Constitución, que lo regulaba en los artículos 231 a 241.

La Comisión de Constitución que se encargó de preparar el proyecto Constitucional contempló al Consejo de Estado en el capítulo VII del título IV. En su discurso preliminar, leído en las Cortes por Argüelles, se manifestaba que el establecimiento de la referida Institución otorgaria al Gobierno la estabilidad y la prudencia que tanto necesitaba, y permitiria salvar a los negocios gubernativos de la arbitrariedad, dirigiéndose a partir de ese momento por principios y

16 Fueron nombrados como consejeros de Estado: Joaquin Blake, Pedro de Agar, Gabriel Ciscar, Luis de Borbon (Cardenal Arzobispo de Toledo), Andrés García Fernandez (arcediano de Vivero), el Marqués de Astorga, el Marqués Del Castelar, Martin de Garay, Melchor José de Foncerrada, Francisco Javier Castaños, José Baquijano y Carrillo, Juan Perez Villamil, José María de Almansa, Pedro Ceballos, Bernardo Ros, Justo María Ibar Navarro, José Aicinena, Antonio Ranz Romanillos, Francisco Requena y Esteban Barea, DSC, 19.02.1812, n 496, pp. $2797-2798$. Especialmente interesante resulta la referencia, incluida en la Guía politica de las Españas para el año 1812, al cursus honorum de los indicados integrantes del moderno Consejo de Estado, pues nos ayuda a conocer la categoría social de las personas que ocuparon este cargo. Decía: "CONSEJO DE ESTADO O DEL REY creado por decreto de las Cortes de 21 de enero de 1812, á conseqüencia de su acuerdo de 9 de diciembre anterior.= D. Pedro Agár, Capitan de navio de la real Armada, director general de las Academias de reales guardias Marinas, è individuo del Consejo de Regencias cesante.=D. Gabriel Ciscar, Gefe de Esquadra de la real Armada, Gobernador de la plaza de Cartagena, electo Secretario del despacho de Marina, è individuo de la propia Regencia.= Emmo. Sr. Carcenal de santa María de Scala. D. Luis de Borbon, Arzobispo de Toledo, Primado de las Españas.= Conde de Altamira, Marques de Astorga. Duque de Atrisco, grande de España de primera clase, Caballero del Toyson de oro y gran Cruz de Cárlos III, Presidente electo del Consejo Real y supremo de las Indias, Gentil hombre de Cámara con exercicio.= D. Andres García, Persbitero, Arcediano de Vivero, y Confesor que fué de la Serenisima Sra. Princesa de Asturias, ya difunta.= Marqués de Castelar, Grande de España de primera clase, Teniente general de los reales exèrcitos, Capitan de la real Compañia de guardias Alabarderos, Caballero gran Cruz de la Orden de Cárlos III, y Gentil-hombre de Cámara con exercicio.= D. Melchor de Foncerrada, Ministro de la real Audiencia de México: por las provincias españolas de ultramar.= D. Martin de Garay, Ministro que era del Consejo de Estado suprimido.= D. Francisco Xavier Castaños, Capitan general de los reales extos., é individuo que fuè del primitivo Consejo de Regencia.= D. José Baquixano, Conde de Vista-florida, Caballero de la real y distinguida Orden española de Carlos III, y Oidor de la real Audiencia de Lima: por las provincias españolas de últramar.= D. Juan Perez Villamil, Caballero de la propia distinguida real Ordne, y Ministro del Consejo supemo de la Guerra.= D. José Mariano de Almansa, Alferez Real, Regior perpétuo de Veracruz, y Ministro honorario del Consejo supremo de Hacienda: por las provincias de ultramar.= D. Pedro Ceballos, Caballero Gran-Cruz de la Orden de Carlos III, primer Secretario que fué de Estado, Ministro del Consjeo suprimido de este nombre; y Enviado que ha sido de la Corte de España cerca de S.M. el Rey de la Gran Bretaña.= El Marqués de Piedra-blanca, electo Regente de la Audiencia de Caracas: por las provincias españolas de ultramar.= D. Justo Maria Ivar Navarro, Ministro del Consejo y Cámara de Castilla.= Dr. D. Josè Ayzinena, Coronel de Milicias y Director de la Sociedad patriótica de Guatemala: por las provincias españolas de ultramar.= D. Antonio Ranz Romanillos, Caballero de la real y distinguida Orden española de Carlos III, Decano del Consejo Supremo de Hacienda, nombrado Secretario interino del despacho de este ramo.= D. Francisco Requena, Ministro del supremo Consejo y Camara de Indias, y Mariscal de Campo de los reales exércitos.= D. Estevan Varea, Secretario del Consejo y Camara de Castilla, y de la Orden española de Carlos III.= NOTA. D. Joaquin Blak, hecho prisionero en Valencia, fuè nombrado primer Consejero de Estado ántes de recibirse aviso de este acontecimiento. Está pendiente de resolucion de las Cortes si con este motivo debe ser ó no reemplazado en este destino, segun lo han anunciado los papels publicos de esta ciudad, Guía politica de las Españas para el año 1812, pp. 188-192. 
máximas por todos conocidas ${ }^{17}$. El debate sobre esta propuesta comenzó el 27 de octubre, extendiéndose hasta el 31 del mismo mes de $1811^{18}$.

\subsection{Sobre la conveniencia de la Administración consultiva.}

De los diarios de sesiones se desprende que existía un acuerdo unánime sobre la necesaria existencia del Consejo de Estado19. En este sentido quisiéramos traer a colación la intervención parlamentaria de José Espiga y Gadea. Este diputado se refería a lo perjudicial que sería para la Nación confiar a un solo sujeto el conocimiento de todos los negocios de la Administración pública. En concreto, negaba que los ministros pudiesen llenar esta facultad por ser amovibles, arbitrarios y no gozar de los conocimientos necesarios a este fin ${ }^{20}$, y

17 “(...) Para dar al Gobierno el carácter de estabilidad, prudencia y sistema que se requiere; para hacer que los negocios se dirijan por principios fijos y conocidos, y para proporcionar que el Estado pueda en adelante ser conducido, por decirlo así, por máximas, y no por ideas aisladas de cada uno de los Secretarios de Despacho, que además de poder ser equivocadas necesariamente son variables a causa de la amovilidad a que están sujetos los ministros, se ha planteado un Consejo de Estado compuesto de proporcionado número de individuos. En él se habrá de refundir el conocimiento de los negocios gubernativos que andaban antes repartidos entre los tribunales supremos de la corte con grande menoscabo del augusto cargo de administrar la justicia, de cuyo santo ministerio no deben ser en ningún caso distraídos los magistrados: y porque también conviene determinar con toda escrupulosidad, y conservar enteramente separadas las facultades propias y características de la autoridad judicial. (...)", Discurso Preliminar a la Constitución de 1812, Centro de Estudios Políticos y Constitucionales, Madrid, 2011, pp. 93-94.

18 Si bien, quedó pendiente la resolución de determinadas adiciones propuestas el día 1 de noviembre por los diputados Traver, Zorraquín y Llaneras, entre otros. El primero pedía se añadiese un artículo posterior al 235 en el que se estableciese lo siguiente: "El Príncipe de Astúrias, luego que cumpla los 18 años, podrá asistir al Consejo de Estado, y le presidirá en ausencia del Rey." Entendía el valenciano, que era conveniente que el heredero a la Corona estuviese en contacto directo, cuanto antes, con los negocios gubernativos. Así, decía, se le facilitaría el entendimiento y estudio de los mismos, DSC, 01.11.1811, n 395, p. 2193-2194. Sin embargo, se consideró improcedente por la Comisión, que dictaminó que la presencia del príncipe podía ser perjudicial “(...) por cuanto por desgracia se hallaba inmediato á la sucesion un Príncipe en quien tuviesen algun influjo las pasiones", DSC, 06.11.1811, n ${ }^{\circ} 400$, p. 2220. Zorraquín, por su parte reclamaba se recogiesen en el mismo artículo los siguientes términos: "Serán propias del Consejo de Estado las demás atribuciones que tuvieren á bien señalarle a las Córtes por reglamento particular que se formará al intento y en conformidad de lo prevenido en la Constitución". Se le contestó que "esencialmente estaba todo comprendido en las palabras del artículo como se halla extendido", DSC, 06.11.1811, n $\mathrm{n}^{\circ} 400$, p. 2220. Por útlimo, la petición de Llaneras consistía en que se declarase "[q]ue en el caso de que algun Obispo sea nombrado Consejero de Estado, deba renunciar al obispado". Pese a que la misma fue objeto de un largo debate, finalmente, el dictamen de la Comisión sería aprobado en todas sus partes, siendo desechadas todas propuestas referidas.

19 La discusión sobre la conveniencia de su existencia se consideró prácticamente innecesaria. Así se desprende, en concreto, de lo manifestado por Creus. De acuerdo con este diputado: "Si se trata de la necesidad de establecer un Consejo de Estado, yo creo que todos estamos convencidos de ella. Pero es preciso saber antes cuáles han de ser sus atribuciones y entonces se podrá fijar el número de individuos que haya de componerse", DSC, 27.10.1811, n³90, p. 2161.

20 “¿(...) se había de confiar á una sola persona el libre despacho de todos los ramos de la administracion pública, y el sublime y delicado encargo de la ejecucion de las leyes, de cuya observancia ó descuido depende la prosperidad ó ruina del Estado? (...) Lejos de nosotros esta conducta impolítica que conduciria á unos extravíos funestos. En vano V.M. habrá sancionado todo lo que hasta aquí ha merecido la aprobación del Congreso, y lo que está para presentarse á discusion, si V.M. no aprueba esta parte tan interesante de la Constitucion (...) ¿La Nación podrá descansar en el dictámen privado de un Ministro que no puede unir todos los conocimientos 
tampoco confiaba en que pudiese hacerlo el rey “(...) de quien si se debe esperar bondad, nobleza y generosidad y buenos deseos, no se puede asegurar ni todos los conocimientos necesarios para el acierto, ni toda la experiencia contra la seduccion (...)"21. En su discurso se mostraba favorable a la regulación propuesta por la Comisión en este punto, que establecía un Cuerpo consultivo:

“(...) que no solo ilustre la dificultad, complicacion y oscuridad de los negocios, sino que contenga la arbitrariedad y haga inútiles todos los esfuerzos de los lisonjeros que por desgracia rodean siempre el Trono y ha formado un Consejo de Estado, en donde se reunan todas las luces de la Nacion, que sea el resultado de la experiencia, el depósito de la sabiduría, y de donde salga la brillante antorcha que ha de dirigir al Rey en la dificil marcha del Gobierno (..."22

Con el objeto de legitimar la Corporación que se trataba de instaurar, el diputado hacía referencia a sus antecedentes históricos. Alegaba que su existencia coincidía con los momentos más gloriosos de la monarquía, aquellos en que la Nación había sido una verdadera potencia, un imperio. Así, se refería al Consejo existente en tiempos del valiente pueblo visigodo, que expulsó de la península a los romanos, los suevos y los vándalos; o al vigente en la época de Enrique III, los Reyes Católicos o Carlos V23. Según el mismo, ésta Institución infundia sabiduría y energía en la actividad del Gobierno, de manera que, en aquellos momentos de la historia en los que se vio debilitada, vencieron la arbitrariedad, la ambición, los abusos y, en definitiva, la tiranía, mientras que cuando le era permitido desarrollar sus funciones con vigor y libertad, regían el orden, la justicia y la prosperidad ${ }^{24}$. De esta forma, fundado en que este órgano contribuiria a poner fin al despotismo, defendia que su instalación era totalmente necesaria en el nuevo régimen constitucional que se trataba de instaurar ${ }^{25}$.

necesarios, de cuya movilidad es tan consiguiente la diversidad de principios como la inconstancia de sistema, y de cuyo influjo nos ha enseñado la experiencia cuánto hay que recelar y temer?”, DSC, 27.10.1811, n 390, p. 2159.

21 DSC, 27.10.1811, n 390, p. 2159.

22 DSC, 27.10.1811, n 390, p. 2159.

23 DSC, 27.10.1811, n 390, p. 2159-2160.

24 "Mientras que se respetaron las resoluciones del Consejo, el Gobierno se expresó con tanta sabiduria como actividad y energía (...). Debilitóse (...) el influjo del Consejo de Estado (...) y las deliberaciones que hasta aqui habian sido el resultado de la experiencia y sabiduría de los hombres más dignos de la Nación, fueron despues el efecto necesario de las sugestiones misteriosas de los Ministros, que abusando de la bondad de los Reyes y de la confianza que les inspiraba su trato frecuente y las ocasiones oportunas, les hicieron servir de instrumentos ciegos de sus intrigas y de sus caprichos (...)", DSC, 27.10.1811, nº 390, pp. 2160-2161. Esta misma afirmación sería realizada, en 1843, por Posada Herrera, señalaba: "Si quisiéramos recurrir á la historia, por ella se comprobaria lo indispensable de la existencia del consejo de estado, pues desórdenes y desgracias grandes, pudiéramos citar, que han sobrevenido en la nacion por la discordancia y falta de sistema, en las disposiciones ministeriales. (...)", José de Posada Herrera, Lecciones de Administración, op.cit., p. 294.

25 "Cuando se considera, Señor, el Consejo de Estado en los diversos tiempos de nuestra Monarquía, ¿puede dudarse de que se ha respetado como un astro benéfico que derramaba sus luces sobre todos los ramos del Gobierno? Cuando se observa que el órden, la justicia y la prosperidad siguieron siempre la línea paralela de la consideración que mereció á los Reyes el Consejo de Estado, ¿se discutirá ni un momento que éste debe ser un cuerpo constitucional? 
Sin embargo, en nuestra opinión, esta alusión a los anales del país no fue más que una argucia. Hay que tener en cuenta que el Consejo de Estado establecido en Cádiz era totalmente diferente del vigente en épocas anteriores. Se trataba de una Institución totalmente nueva, de inspiración francesa ${ }^{26}$. De acuerdo con Jordana de Pozas, la razón que explica este recurso a lo histórico es el sentimiento patriota de los diputados, que hizo que presentasen sus innovaciones como una adaptación de las vetustas Corporaciones españolas ${ }^{27}$. Igualmente hay que tener presente, como manifiesta Fernández Sarasola, que el país vecino era en esos momentos el enemigo, pudiendo encontrar las reformas pretendidas grandes dificultades si su justificación se basaba en la imitación del modelo galo ${ }^{28}$. Así pues, siguiendo esta solución, y de acuerdo con Tomás De La Quadra-Salcedo, la referencia histórica sería una mera estrategia de camuflaje ${ }^{29}$.

En conclusión, se puede afirmar que entre los diputados gaditanos existía el convencimiento de que la existencia del referido Cuerpo consultivo resultaba imprescindible para la correcta dirección de la Administración pública. Lo mismo se puede afirmar con respecto a la doctrina, que entendía que dicho órgano sería un freno a la incompetencia y arbitrariedad del Gobierno ${ }^{30}$. También la prensa

Cuando se ve que en todos los tiempos ha sido el blanco de los tiros de los Ministros, ¿no es éste un testimonio bien cierto de que solo él puede contener la arbitrariedad ministerial? No dude V.M. un instante de su establecimiento: él solo podrá ilustrar á los Reyes para que no sean jamás sorprendidos por la seducción de los privados, y él solo podrá descubrir los caminos tortuosos por donde se les hace marchar hasta llegar á la ruina de la Nacion.”, DSC, 27.10.1811, n 390, p. 2161 .

26 Así, Ignacio Fernández Sarasola, "El primer liberalismo en España (1808-1833)", Historia Contemporánea, $n^{\circ}$ 43, 2011, p. 564; y Luis Jordana de Pozas, El Consejo de Estado español y las influencias francesas a lo largo de su evolución, op.cit., p. 20.

27 Luis Jordana de Pozas, El Consejo de Estado español y las influencias francesas a lo largo de su evolución, op.cit., p. 20-21. Señala este autor un aspecto muy importante a tener en cuenta y es que el influjo mencionado fue principalmente dimanante de la doctrina de la separación de poderes, sin que exista una imitación del Consejo napoleónico ni de su réplica de 1808. 565.

28 Ignacio Fernández Sarasola, “El primer liberalismo en España (1808-1833)”, op. cit., pp. 564-

29 Tomás De La Quadra-Salcedo, "El Consejo de Estado en las Constituciones de Cádiz y Bayona”, Revista de Documentación Administrativa, n²44-245, 1996, pp. 14-15.

30 A modo de ejemplo, encontramos esta afirmación en la obra titulada Catecismo político arreglado á la Constitución de la Monarquía española para la ilustración del pueblo, instrucción de la juventud y uso de las escuelas de primeras letras. Decia: "P. ¿Pero no pudiera el rey y el secretario del despacho errar sin malicia, y solo por equivocación ó falta de conocimiento en la materia?= R. Para obviar este mal, y tanto con el objeto de no dejar disculpa alguna á los secretarios, como para coartar su demasiada influencia, hay un consejo de estado, que es el único consejo del rey, quien está obligado á oir su dictámen, (aunque sin precision de seguirle) en los asuntos graves gubernativos, y señaladamente para dar ó negar la sancion á las leyes, declarar la guerra y hacer los tratados. (Art. 236.)", D.J.C., Catecismo politico arreglado á la Constitución de la Monarquía española para la ilustración del pueblo, instrucción de la juventud y uso de las escuelas de primeras letras, Barcelona, 1820, p. 65. El mismo alegato sostendría, años más tarde, Posada Herrera, al señalar que: "No solo es necesaria la creacion de un consejo de estado, para que aconseje á los ministros en la resolucion de los negocios árduos y graves, de los cuales no pueden enterarse por si detenidamente, y meditarlos en la calma que de suyo exijen, sino que es necesaria tambien para dar unidad y enlace á la administracion, á fin de que en todas sus disposiciones generales se siga un mismo principio y sistema. (...)", José de Posada Herrera, Lecciones de Administración, op.cit., p. 293. 
apreciaba sus bondades. En este sentido, conviene traer a colación la publicación del Diario Patriotico de Cadiz, que señalaba:

"Asi es que segun este órden de cosas la Patria existe, y existe con una vida durable y constante y con salud y próspera robustez. Y si por la órden de san Fernando se renueva la nobleza y se hace efectiva y personal, en el Consejo de Estado se restaura la verdadera grandeza española, y se hace práctica y estimuladora á las grandes y constantes virtudes públicas, de que únicamente debe ser el premio la plaza de Consejero de Estado á quien el Rey agraciará con la Grandeza"31.

Existía, por tanto, un acuerdo generalizado de que su instauración solo conllevaría beneficios, eliminando todo rastro de despotismo ministerial. El punto de discordia vino, sin embargo, representado por la composición y funciones que debian atribuirse al mismo.

\subsection{El debate sobre la composición del Consejo de Estado.}

Los artículos 230 y 231 del proyecto de constitución fijaban en cuarenta el número de consejeros, distribuidos del siguiente modo: cuatro eclesiásticos, y no más, constituidos en dignidad, y de los cuales dos deberian ser obispos; cuatro grandes de España, y no más, "adornados de las virtudes, talento y conocimientos necesarios"; y treinta y dos individuos distinguidos por su probidad, instrucción y servicios en las carreras diplomáticas, militar, económica o de magistratura. Establecía, asimismo, la incompatibilidad de este oficio con el de diputado y señalaba la necesidad de que, de los individuos que lo compusiesen, doce pertenecieran a las provincias de ultramar ${ }^{32}$.

Esta especial estructura venia justificada en el Discurso Preliminar a la Constitución, según el cual se establecía un número fijo de individuos del clero y de la nobleza para dar "consideración y decoro a tan señalada reunión"33. De igual manera, se entendia necesaria la presencia de representantes de los territorios de ultramar,

“(...) para que de este modo se estreche más y más nuestra fraternal unión, pueda tener el Gobierno prontos para cualquier resolución todas luces y conocimientos que necesite y aquellos paises el consuelo de

31 Diario Patriotico de Cadiz, $\mathrm{n}^{\circ}$. 85, sábado, 29 de enero de 1814, p. 903. El subrayado es nuestro.

32 "Estos serán precisamente en la forma siguiente; á saber: quatro eclesiásticos, y no mas, constituidos en dignidad, de los quales dos serán obispos; quatro grandes de España, y no mas, adornados de las virtudes, talento y conocimientos necesarios; y los restantes serán tomados de los sugetos que sirvan ó hayan servido en las carreras diplomáticas, militar, económica y de magistratura, y que se hayan distinguido por su talento, instruccion y servicios. Las Córtes no podrán proponer para estas plazas á ningun individuo que sea diputado de Córtes al tiempo de hacerse la elección. De los individuos del Consejo de Estado doce á lo menos serán de las provincias de ultramar", José $\mathrm{M}^{\mathrm{a}}$ Martín Oviedo, El Consejo de Estado durante el régimen constitucional (1808-1812), op.cit., documento anexo $\mathrm{n}^{\circ} 11$, tomado, a su vez de Alguacil Prieto María Luisa, Constitución de 1812: Sintesis cronológica de la elaboración y aprobación del proyecto.

33 Discurso Preliminar a la Constitución de 1812, op.cit., p. 94. 
aproximarse por este nuevo medio al centro de la autoridad y de la madre patria"34.

Es importante señalar que cláusula "y no más" que se introdujo en las categorías de eclesiásticos y grandes de España fue considerada por la opinión pública como oportuna y prudente. Así, el Semanario patriótico manifestaba, en 1811, lo siguiente:

“(...) No se queria ver que el objeto de la comision habia sido que el consejo de estado, que nada tiene de divino, de espritual, ni de junta de conciencia, no tuviese el aspecto de concilio nacional como no dexaria de verificarse si atendemos a la influencia del clero, demostrada en la eleccion de diputados de cortes. ¿Acaso el consejo de estado ha de tratar puntos de disciplina? ¿acaso para proponer los beneficios, prebendas, dignidades y mitras, ha sido hasta ahora, ni es necesario ser beneficiado, canónico ni obispo? ¿acaso no es conveniente disminuir los pretextos con que los pastores abandonan sus rebaños? (...)"35

El nombramiento de los consejeros correspondía al rey a propuesta de las Cortes en pleno ${ }^{36}$. Éstas debian formar una lista triple de la cual el monarca elegiría a los cuarenta individuos, tomando los eclesiásticos de la lista de su clase, los grandes de la suya, y así los demás ${ }^{37}$. La finalidad de este procedimiento era, según el reseñado Discurso Preliminar tratar de evitar que el Consejo fuese visto como un Senado temible por su origen. De esta manera, todas las partes salian victoriosas: de un lado, la Nación contaría con patriotas en el seno de la referida Institución, de otro, el soberano tendría la facultad de seleccionar a aquellos sujetos que le inspirasen más confianza y, por último, los consejeros, que eran inamovibles, no encontrarian ningún obstáculo a su

\footnotetext{
34 Discurso Preliminar a la Constitución de 1812, op.cit., p. 94.

35 Semanario patriótico, n LXXXVII, jueves, 5 de diciembre de 1811, pp. 34-35.

36 Artículos 232 y 233 del proyecto constitucional.
}

37 La idea inicial prevista por el Proyecto de Constitución era algo distinta. Así, el artículo 233 estaba, inicialmente, redactado en estos términos: "Para la formación de este Consejo se dispondrá en las Córtes, comprometiéndose éstas en una Comision de 12 Diputados, una lista triple de todas las clases referidas en la proporcion indicada, de la cual el Rey elegirá los individuos que han de componer el Consejo de Estado, tomando los eclesiásticos de la lista de su clase, los grandes de la suya, y así de los demás". Argüelles trató de justificar la necesaria existencia de una Comisión alegando la dificultad de que el pleno de las Cortes pudiese encargase de formar la lista triple, calificándola de una "operación, además de aventurada, casi impracticable. Un mes entero de sesiones dedicadas á arreglar este punto, apenas sería suficiente (...)", DSC, 31.10.1811, n 394, p. 2184. Sin embargo, sus esfuerzos fueron en vano. La opción de que la elección de los consejeros de Estado se hubiese de realizar por una "Comisión de 12 Diputados" levantó muchas opiniones en contra. Así, Aner, se opuso de inmediato a la misma, argumentando que “(...) este modo de proceder seria contrario á la libertad que todos los Diputados deben tener para proponer las personas que en su concepto entiendan ser más beneméritas (...)". De la misma opinión era Zorraquin, que consideraba necesario que "las Córtes oigan el voto de todos sus Diputados en semejante propuesta, sin que pueda decirse fundadamente que el no querer el compromiso de los 12 designados, no es por falta de confianza, sino por falta de conocimiento prévio de los sugetos beneméritos que haya en las provincias, los cuales estarán más al alcance de todos los Diputados, que de solos 12 (...)". Por ello solicitaba que se suprimiesen del artículo las palabras referentes a la Comisión, proponiendo que se redactase del modo siguiente: "para la formacion de este Consejo se dispondrá en las Córtes de una lista triple de todas las clases referidas en la proporción indicada, de la cual, etcétera, etc". Propuesta que secundaron los diputados Canaleja y Gallego, DSC, 31.10.1811, n 394, p. 2184-2185 
independencia ${ }^{38}$. Esta forma de elección fue, sin embargo, duramente criticada por el diario El Sensato, al considerar que en ella estaba muy limitada la intervención del monarca, privándosele de una de sus facultades más relevantes y convirtiendo al Cuerpo consultivo en una entidad aislada ${ }^{39}$.

El debate parlamentario sobre la composición de la nueva Corporación fue muy intenso. Buena parte del Hemiciclo entendia que, atendiendo a razones de indole económico y competencial, debía reducirse el número de sus integrantes. De este parecer era el Conde de Toreno. Entendía este grande de España que, atendiendo a las funciones que se le habian señalado, debía reducirse a veinticuatro el número de sus componentes. De lo contrario, afirmaba, se entorpecería al Poder ejecutivo y se haría sombra al legislativo ${ }^{40}$.

38 “(...) la nación (...) tendrá seguridad de no contar entre sus individuos personas desafectas a los intereses de la patria; y el Rey quedando en libertad de elegir de cada tres uno, no se verá obligado a tomar consejo de súbditos que le sean desagradables. Últimamente, la seguridad de no poder ser removidos de su encargo sin causa justificada de los individuos del Consejo de Estado, afianza la independencia de sus deliberaciones, en que tanto puede influir el temor de una separacion violenta o poco decorosa.", Discurso Preliminar a la Constitución de 1812, op.cit., p. 94.

39 “El Rey viene á ser una persona moral, nada segun el proyecto de la Constitucion á pesar de las facultades que á primera vista se presentan, pues que no solo se le obliga á confesar públicamente que no tiene parte en la legislacion con la fórmula que se establece para la promulgacion de las leyes, (...) no solo se le excluye como á sus Ministros de la asistencia á las deliberaciones de las Cortes, que se permite á todo el mundo, que en Inglaterra se practica con tan buen exito, como acredita la felicidad de la Nacion, sino que aun las mismas facultades que se señalan por el artículo 171, y que á primera vista parecen grandes, son nada, como se acreditará del exàmen de algunas de las que parecen mayores (...)= La quarta y sexta al paso que presentan la provision de las Magistraturas, Obispados, y Beneficios eclesiásticos anexa á su autoridad, ademas de que pueden reducirse á la nulidad suprimiendo todas ó las mas de aquellas en uso de la citada facultad nona de las Córtes, y alterando el metodo de la provision de estos á pretexto de reforma de este nombre que constantemente ha servido de velo a todos los novadores como se exige por el articulo 236, sea á propuesta por terna del Consejo de Estado la depositan efectivamente en este cuerpo, cuyos individuos son elegidos casi sin intervencion del Rey, segun la formula del articulo 233 y en nada dependen de él, pues que ni los puede remover ni señalar sueldo, segun los 238 y 239.”, El Sensato, n ${ }^{\circ}$ 35, jueves, 30 de abril de 1812, pp. 569-574. E1 subrayado es nuestro.

40 “(...) debiendo el Rey tener un Consejo, no mejor forma puede dársele que haciéndole emanar de las Córtes, ó siendo elegido á propuesta suya; pero me parece excesivo el número de individuos que se señala. (...) Y si nos detenemos á examinar las facultades que en el mismo proyecto de Constitución se señalan al Consejo de Estado, es de notar que en él se fijan solamente como peculiares suyas las de proponer para todos los empleos civiles y eclesiásticos, y la de ser oido por el Rey en los asuntos graves. Pero como no se especifica nominalmente cuándo ó cómo se han de calificar estos detalles, queda á la voluntad del Rey el determinarlos, y entonces no serán tantos los casos en que se acuda á pedir su dictámen. Tampoco podemos prescindir del sistema adoptado en esta Constitucion, que es el de una Monarquía moderada. En ella ni se necesita ni es de su esencia un Consejo ó Senado tan numeroso que, aunque no sea como el de Suecia, siempre entorpecerá al Poder ejecutivo y hará sombra al legislativo (...) Asi, quedando circunscritas las facultades ó atribuciones del Consejo de Estado á las ya señaladas por la comision, opino se reduzcan á 24 sus individuos (...)", DSC, 29.10.1811, n ${ }^{\circ}$ 392, p. 2170. Esta misma idea era sostenida por Castelló, que consideraba que las competencias del Cuerpo consultivo debían ser todavía más reducidas, eliminándose de su seno las consistentes en presentar los beneficios eclesiásticos y de proveer las plazas de judicatura. Para el valenciano éstas facultades debian ser atribuidas a la Nación, que las ejercería a través de sus representantes en las Cortes. Decía: "No me opongo al establecimiento del Consejo de Estado; pero si á que sea tan numeroso como lo pone en el proyecto de Constitucion y con las atribuciones que señala. Estamos conformes en que tenga el Rey un cierto número de hombres de bien, sábios, experimentados y de acreditada conducta, nombrados por él mismo á propuesta de las Córtes, con quien consulte cuantos 
A argumentos de carácter económico se refería el diputado Terrero. Mantenía que la disminución a la mitad de los consejeros supondría al erario público un ahorro de un millón de reales. Gasto superfluo que era oportuno evitar, dada cuenta de las necesidades por las que estaba pasando el país ${ }^{41}$. De la misma opinión era Gordillo, que lo consideraba como un dispendio innecesario al que calificaba de "crimen imperdonable". Además, añadia, esta multitudinaria composición supondría un obstáculo a la imprescindible energía que debía caracterizar a las providencias del Gobierno. Obligado éste a consultarle en los asuntos más graves, vería frenada su actividad por la lentitud y dificultad que presidiría en la referida Institución a la hora de tomar sus acuerdos. Sostenía, igualmente, que los males que se habian tratado de evitar por la Comisión, esto es, prevenir la intriga y asegurar la claridad y el acierto en la discusión de los negocios, estaban salvados con una cifra más reducida de integrantes. No cabía olvidar, decía, que de un lado, los miembros que iban a formar parte del referido órgano debian ser presentados al rey por las Cortes, quienes seleccionarian a los sujetos más distinguidos por su talento, virtud y patriotismo. En su opinión, un número de veinticuatro o veinticinco integrantes sería más que suficiente para desempeñar las facultades que les eran encomendadas ${ }^{42}$.

asuntos se le ofrezcan en el desempeño de su alto ministerio; pero no lo estamos en que estos consejeros sean los que por ternas propongan al Rey para la presentacion de los beneficios eclesiásticos y para la provision de las plazas de judicatura. Estas y otras atribuciones semejantes, cuyo ejercicio tanto interesa al Estado, debieran residir en la Nacion representada por las Córtes cuando se hallaren juntas, y cuando no lo estuvieren (...) por un competente número de Diputados de cada reino ó provincia, en proporcion, elegidos por las mismas antes de disolverse. (...) mi opinion se ciñe á que se reduzca el número del proyectado Consejo de Estado y se aumente el de la Diputacion permanente de Córtes, y que corran al cargo de esta, así las propuestas para los beneficios eclesiásticos y plazas de judicatura, atribuidas al Consejo, como de cuanto pueda influir directa ó indirectamente en el bienestar de la Nacion", DSC, 27.10.1811, ${ }^{\circ}$ 390 , p. 2158.

41 “(...) ¿y para esta presentacion de ternas, y dar un simple consejo han de ser necesarios 40 individuos? Yo no sé por qué, ni para qué. (...) Las propuestas de los empleos se hacian anteriormente, y se hacian por un corto número de sugetos: pues ¿por qué no han de poder hacerse por 20 indivíduos? ¿Y por qué estos mismos no podrian tambien dar un dictámen juicioso al Monarca? Por otra parte, la necesidad de cercenar los dispendios del Erario no es pequeña, y debe entrar en gran consideracion; porque no es cosa de juego el ahorro de un millon de reales, que se verificaria reduciendo á la mitad el número de los indivíduos de ese Consejo de Estado", DSC, 29.10.1811, n 392, p. 2170.

42 “(...) exigiendo los peligros que amenazan á la Monarquía el que el expediente de las providencias del Gobierno sean enérgicas y ejecutivas, esta rapidez y actividad no es componible con el embarazo y entorpecimiento que es inseparable de las resoluciones que dimanan de la conformidad de una muchedumbre de votos dificiles de reunirse por naturaleza sin muchos debates y contradicciones (...) Los motivos que pudieron mover á la comision á señalar los 40 individuos constituyentes del Consejo de Estado, es presumible que no hayan sido otros sino los de prevenir la intriga y partidos demasiado fáciles y frecuentes en una corta reunion de hombres, y asegurar la claridad y acierto en la discusion de los negocios, que parecen ser más asequibles y efectivos cuando intervienen las luces y conocimientos de un crecido número de personas (...) cuando se trata del nuevo Consejo de Estado, yo no puedo prescindir de que los españoles que le constituyan han de ser presentados por las Córtes, y que éstas, teniendo en consideración las altas funciones de su competencia y el poderoso influjo que habrán de ejercer en el Gobierno del Rey para el bien ó perjuicio de la Nacion, han de depositar sus confianzas en los ciudadanos más distinguidos por sus talentos, por su ciencia, por su probidad, por su vitud, por su mérito y patriotismo; los cuales, por su carácter y gloria de su propio nombre, han de resistir abiertamente las miserables sugestiones de la confabulacion, del fraude y de la intriga (...) el mismo proyecto de Constitucion es un testimonio irrefragable de que á una pequeña reunion de hombres le es dado 
Pese a los referidos argumentos, la mayor parte de los diputados se mostró favorable a que el alto Cuerpo consultivo estuviese compuesto de cuarenta individuos, siendo finalmente aprobado el artículo 230 del proyecto de Constitución en la sesión de 29 de octubre de 1811. Las razones apuntadas para su defensa se concretaban, en primer lugar, en que el Consejo de Estado actuaría de correctivo ante la posible "impetuosidad" que pudiese existir en la Asamblea legislativa como consecuencia de la inexistencia de una cámara alta que permitiese la meditación y sabiduría; y seguidamente, que dicha composición venía exigida por el gran número de negocios que, dispersos hasta el momento, se concentrarian en la referida Institución ${ }^{43}$, obligándola a su división en distintas secciones $^{44}$.

manejar con cordura y discrecion los puntos más difíciles y árduos, pues formado por solo 15 Diputados, resplandece en él tanto órden y exactitud, que las Cortes apenas han tenido que alterar ó añadir lo que la comision tuvo á bien omitir, sin duda por su natural delicadeza y circunspección (...) juzgo (...) que el nuevo Consejo de Estado se componga de solos 24 ó 25 indivíduos, por ser los suficientes para desempeñar los objetos de su instituto: este es mi dictámen, sin embargo del cual respetaré lo que V.M. se dignare a resolver.”, DSC, 29.10.1811, n 392, p. 2171-2172.

43 Esta fue, en concreto, la postura que adoptó Argüelles quien reconoció que, en un principio, también a él le había parecido excesiva la cifra de cuarenta individuos, pues pensaba que: “(...) unos hombres propuestos por las Córtes y nombrados por el Rey, que no pueden ser removidos de sus destinos sino por justa causa probada en juicio contradictorio, acompañados del explendor del poder, y colocados al lado del Rey y en la córte, formarian un cuerpo aristocrático, que podía hacer sombra al Cuerpo legislativo, cuyos individuos regularmente no tendrán todas aquellas condecoraciones y prestigios que acompañan á los Consejeros de Estado", DSC, 27.10.1811, $\mathrm{n}^{\circ}$ 390 , p. 2158. No obstante lo expuesto, el asturiano acabó sometiéndose a los argumentos dados por el resto de comisionados por las razones apuntadas, que el mismo defendió. A esta conclusión llegó también Tomás y Valiente, que preguntándose por la razón que llevó a Argüelles, pese al temor que residía en él de que el Consejo de Estado se convirtiese en una segunda cámara, a plegarse a la voluntad mayoritaria dentro de la Comisión y defender dicha tesis en el pleno de las Cortes, consideró que era por el gran volumen de negocios que la nueva Corporación debería asumir, interviniendo "en todos los asuntos gubernativos que hasta el momento se distribuian entre todos los Consejos del precedente régimen polisinodial: que uno que hereda tanto, sea un cuerpo numeroso en su composición, no parece descabellado.", Francisco Tomás y Valiente, "El Consejo de Estado en la Constitución de 1812", Revista del Centro de Estudios Constitucionales, $\mathrm{n}^{\circ}$ 21, 1995, p 15.

44 Además de Argüelles, mostraron su conformidad con el número de componentes que la Comisión había otorgado al cuerpo consultivo los diputados Giraldo, Pérez de Castro, Villanueva, y Villagómez. Todos coincidian en que el gran número de facultades que asumiría el Consejo de Estado obligaría a su división en secciones en función de la materia, siendo necesario la existencia de un número suficiente de consejeros en cada una de ellas para que se pudieran adoptar los más acertados acuerdos. Como ejemplo de estas intervenciones, que tuvieron lugar entre el 27 y el 29 de octubre de 1811, traemos a colación, por su claridad, la del diputado Giraldo. Decía: “(...) Hemos de considerar el estado en que quedará la Nacion despues de expelido el enemigo de nuestro territorio. El cúmulo de asuntos que tanto de la Península como de la América abrumarán entonces á ese Cuerpo. Reducidas á cinco sus secciones, resultarán ocho indivíduos por cada una de las salas. Ellos habrán de entender en asuntos de caminos, canales, montes, etc., y lo que menos tendrán que hacer será en las propuestas de las ternas (...) Así, yo suplico á V.M. no se pare un momento en el número de indivíduos que hayan de componer ese Consejo de Estado; pues cuando se trata del bien de la Nacion, ni debe detenernos una consideracion de tan poca entidad, ni la dificultad de los gastos, que es cosa muy miserable respecto de las ventajas que han de resultarnos". DSC, 27.10.1811, no 390, pp. 2158-2159. En el mismo DSC, p. 2159, la intervención de Pérez de Castro. Las de Villanueva y Villagómez, por su parte, en DSC, 29.10.1811, nº 392, pp. 2172-73. 
A estas razones añadía Pérez de Castro que los destinados a formar parte del Consejo contarian con una gran trayectoria en sus carreras y esto, a su vez, implicaría que la mayoría de ellos tendría una edad avanzada lo que, "(...) unido a los achaques ó indisposiciones de unos, y á la ausencia temporal de otros, no dejará de producir la falta de asistencia ó trabajo habitual de algunos (...)"45. Asimismo, ante las alegaciones de indole económico que argüían los contrarios a tan amplia configuración, afirmaba que no se pretendia un establecimiento inmediato, sino que se preveía llevarlo a cabo “(...) cuando libre y desembarazada la Nación puedan escogerse los más beneméritos entre la universalidad de los ciudadanos, y no sea un inconveniente dotar estas plazas con la conducente economía"46.

Otra cuestión controvertida, y directamente relacionada con la composición, fue la inamovilidad de los consejeros. En contra de la misma se manifestó el diputado Gordillo, para quien el cargo debía ser temporal. En su opinión la necesidad de conservar el buen nombre y la voluntad de volver a ser escogidos motivaría a sus ocupantes a desempeñarlo con la mayor vocación y probidad. Por el contrario, con la perpetuidad solo se lograría que quienes lo desempeñasen lo hiciesen de forma arbitraria e irresponsable. Por esta razón proponía que se reformase el artículo 238 en los siguientes términos: "Los Consejeros de Estado serán amovibles (aquí el tiempo que el Congreso señalare), y en este tiempo no podrán ser removidos sin causa justificada ante el Tribunal Supremo de la Nacion" 47.

No fue bien acogida esta propuesta. Los defensores del carácter vitalicio del puesto se basaban, en primer lugar, en que la seguridad que en ellos produciria su permanencia en el cargo derivaría en un mayor interés en el ejercicio de su labor; en segundo lugar, en que se trataba de un cargo elevado, de dificil alcance y “(...) nada hay más justo que el que en todas las carreras haya ciertos destinos superiores de honor y descanso á que aspiren los que profesan, y cuya esperanza sea un estímulo constante mientras ocupan los puestos inferiores (...)"48; y,

45 DSC, 27.10.1811, n 390, p. 2159.

46 DSC, 27.10.1811, nº 390, p. 2159.

47 “(...) No se necesita mucho detenimiento para comprender la grande utilidad que resultaria á los pueblos de que los superiores destinos de la Nacion sean amovibles dentro de un fijo y señalado término, así porque salta á la vista la conveniencia de que todos los indivíduos del Estado que reunen el talento, los conocimientos, la probidad y el patriotismo, tengan una opcion inmediata á puestos tan elevados, como porque circulando estos en un espacio de tiempo determinado, se generalizará el estímulo del mérito y la virtud, y los amantes de la gloria se empeñarán en adquirir las relevantes cualidades que los hagan dignos de obtenerlos: esta observacion se consolida mucho más si se meditan los absurdos y abultados inconvenientes que por una infalible consecuencia dimanan de la estabilidad de los empleos, porque si es una verdad que los que poseen con tal seguridad se abandonan á un conocido entorpecimiento y criminal indiferencia en el cumplimiento de sus deberes, no lo es menos que contraen una especie de arbitrariedad y despotismo, que haciéndoles despreciar la observancia de las leyes y las bases del interés comun, reduce á ser el frágil jueguete de la voluntariedad, del capricho y de otras vergonzosas pasiones (...)", DSC, 31.10.1811, n 394, p. 2188.

48 En estos términos se expresaba, en concreto, el diputado Gallego, quien aseguraba que: “(...) Es indudable que cuando el hombre está seguro de que sin motivo justo no puede ser removido de su empleo, lo mira en cierto modo como una propiedad, toma interés en los asuntos en que se ocupa, y se envanece con los progresos ó mejoras que por su celo se notan en los negocios de su cargo. No sucede así con los empleados temporales, en los cuales es preciso se echen de ver los mismos defectos de los interinos. No abandonarán escandalosamente sus obligaciones; pero 
finalmente, en lo costoso que sería para el erario público mantener a los consejeros cesantes ${ }^{49}$.

Favorables a su perpetuidad se manifestaron, igualmente, los redactores del Semanario patriótico, que resaltaban la necesaria estabilidad de que debía gozar esta Institución al requerir sus deliberaciones un examen detenido y profundo ${ }^{50}$. Este mismo argumento sería, posteriormente, defendido por el propio Posada Herrera, que afirmaba: “(...) La movilidad de los gobiernos representativos, hace referencia mas bien á la marcha política que administrativa. La administracion de un pais para ser buena, no ha de sufrir esos sacudimientos violentos, á cuyo impulso caen con frecuencia los ministerios (...)"51.

En conclusión, del examen de los debates parlamentarios relativos a la configuración del Consejo de Estado se puede apreciar la trascendencia que los diputados vaticinaban a esta Institución. Tanto es así que se consideró imprescindible dotarla de una numerosa composición en base al gran número de cuestiones a las que debería dedicar su atención y a la especial relevancia de las mismas, haciendo caso omiso de las razones de índole económico que aconsejaban lo contrario. Siendo una Corporación tan importante para el devenir del Estado, su instauración, no cabe duda, solo podía considerarse como de imperiosa necesidad.

\subsection{En torno a las competencias del superior cuerpo consultivo.}

El artículo 235 del proyecto constitucional establecía que "El Consejo de Estado es el Consejo del Rey, que oirá su dictámen en los asuntos graves, señaladamente para dar ó negar la sanción á las leyes, declarar la guerra y hacer los tratados" 52 . Se trata, como se puede apreciar, de un precepto muy ambiguo que fue, rápidamente, reclamado por la opinión pública. En este sentido, es necesario citar las palabras del Semanario patriótico, según el cual se había dejado a la determinación del Gabinete ministerial la selección de los asuntos que

tampoco habrá muchos que las desempeñen con aplicacion y esmero. Los más irán á lo que se llama salir del dia, ya que no se dediquen exclusivamente á hacer su negocio (...)", DSC, 31.10.1811, n 394 , p. 2188.

49 Así, sentenciaba Gallego: “(...) ¿qué haria el Gobierno de los consejeros de Estado que fuesen cumpliendo su tiempo? ¿Volverles su anterior empleo? Y el que hasta allí lo hubiese desempeñado, ¿lo habría hecho en calidad de interino, que tantos perjuicios acarrea? ¿O bien se quiere que llegado el término á los consejeros se grave el Erario público con cuantiosas y multiplicadas jubilaciones?”, DSC, 31.10.1811, n 394, pp. 2188-2189.

50 "Si nos hacemos cargo de que la primera cualidad del consejo de estado debe ser el seso, la madurez y la paciencia en las deliberaciones, producto todo de la práctica y de la experiencia en los negocios; que ha de ser un crisol donde se prueben las resoluciones, una maquina prolixa que descubra las faltas de las providencias que medite el gobierno y sus ministros; se verá el acierto con que está extendido el artículo 231, que destina las plazas de consejeros de estado para los sugetos que sirven ó hayan servido en las carreras diplomática, militar, económica, y de magistratura; y que se hayan distinguido por su talento, instruccion y servicios. De aqui resulta á nuestro entender una imposibilidad de que los consejeros de estado, si el consejo ha de llenar su instituto, sean amovibles (...)", Semanario patriótico, $\mathrm{n}^{\circ}$ LXXXVII, jueves, 5 de diciembre de 1811, pp. 39-40.

51 José de Posada Herrera, Lecciones de Administración, op. cit., p. 297.

52 DSC, 31.10.1811, nº 394, p. 2186. 
debían someterse a conocimiento de la Corporación, condenándola, de esta manera, a la inacción ${ }^{53}$. Decía:

"No convenia (...) dexar al arbitrio de los ministros los casos en que se hubiese de consultar al consejo de estado; sino que se le debia oir en todo negocio grave, $y$ en toda providencia general. Los ministros llevarian solo la rutina, las ordenes de execucion, y los asuntos particulares, pero de mera formalidad. (...) la creacion del tribunal es á fin de que el gobierno tenga un sistema uniforme y no vario, segun los planes ó ideas de cada ministro, de cada ramo, y de cada persona. Lo qual no se consigue con el diminuto artículo 235 (...)"54

Esta redacción tan indefinida también levantó un importante debate en el seno de las Cortes. Varios diputados reclamaron una mayor concreción y especificación de las funciones del Cuerpo consultivo. En concreto, José Martínez advertía que la indeterminación de sus facultades, conllevaría dejar a la voluntad del monarca la intervención del Cuerpo consultivo en negocios de real importancia, por eso solicitaba que se diese a la referida disposición la siguiente redacción:

"El Consejo de Estado es el Consejo del Rey, que oirá su dictámen en todos los asuntos graves relativos á la administracion general del Reino, en que hasta aquí gubernativamente entendieron los Consejos, Cámaras, Juntas de comercio y cualesquiera otra comision especial establecida en la córte, y señaladamente para dar ó negar la sancion á las leyes, declarar la guerra, hacer los tratados y cualesquiera otros negocios que haya de fijar una ley ó resolucion general" 55

Espiga, por su parte, proponía se añadiese, al final del indicado precepto, las palabras "y en aquellos negocios en que haya de establecerse regla general para la mejor ejecucion de las leyes"56. Con esta adición, señalaba, se evitaría que los ministros viendo a la señalada Institución como un embarazo a su libre acción, minasen sus funciones y acaparasen los negocios más graves, dejándola vacia de contenido 57 .

53 "El artículo, segun está, es vago é indeterminado. ,¿¿Quién ha de graduar la gravedad de los negocios? Preguntaba con mucha razon el señor Espiga. Los ministros, que no pueden menos de mirar el consejo de estado como un embarazo que se opone á la extension de sus facultades, y á la libertad á que siempre aspiran en el despacho...Acordémonos que desde su creacion los negocios de gobierno fueron el objeto de su institucion, y no olvidemos que los ministros no solo consiguieron menoscabar sus facultades; sino tambien suspender sus sesiones, y convertirle en un ruinoso ostracismo (...)", Semanario patriótico, $\mathrm{n}^{\circ}$ LXXXVII, jueves, 5 de diciembre de 1811 , p. 38.

54 Semanario patriótico, $\mathrm{n}^{\circ}$ LXXXVII, jueves, 5 de diciembre de 1811 , p. 38.

55 DSC, 31.10.1811, n 394, p. 2188.

56 DSC, 31.10.1811, n 394, p. 2188.

57 “(...) La comision ha creido que seria bastante señalar los negocios árduos; pero ¿quién ha de graduar estos? ¿No serán los Ministros los que decidan esta cuestion? Y no pudiendo menos los Ministros de mirar al Consejo de Estado como un embarazo que se opone á la extension de sus facultades, y á la libertad á que siempre aspirarán en el despacho, ¿será extraño que con varios pretestos, con que por desgracia no es dificil sorprender a los Reyes, se vayan reservando sucesivamente los negocios graves, y que el Consejo venga á un estado en que ya no se le consulte sino sobre la guerra y la paz?, DSC, 31.10.1811, n 394, p. 2186. 
Triunfó, sin embargo, el dictamen de Aner, que se pronunció en contra de la variación del señalado artículo 235. Basaba su oposición en que atribuir al Consejo de Estado la facultad de conocer sobre todo lo gubernativo era un sinsentido pues, de un lado, ya existía un Ministerio de la Gobernación del Reino encargado de muchos de esos asuntos, y, por otro, esto solo supondría un notable atraso en el despacho de los negocios, coartando las facultades del monarca ${ }^{58}$.

Finalmente, quedó esta Institución consagrada en los artículos 231 a 241 de la Constitución cuyo texto venía a coincidir, a grandes rasgos, con el plasmado por la comisión en el Proyecto de la misma59. El 21 de enero de 1812 se publicó el Decreto de Cortes según el cual éstas habian determinado elegir veinte consejeros, de los cuales seis serían naturales de las provincias de Ultramar, dos eclesiásticos y dos grandes de España.

De lo hasta aquí analizado podemos concluir que la finalidad de los constituyentes al crear el Consejo de Estado fue, por un lado, establecer un mecanismo de control sobre el Ejecutivo ${ }^{60} \mathrm{y}$, por otro, instaurar una Corporación que, en defecto de una Cámara alta, ejerciese de intermediario entre el Gobierno y el Parlamento. Ejemplo claro es la necesaria consulta que el rey debía realizar a este órgano de forma previa a sancionar las leyes. Se trataba, como manifiesta Tomás y Valiente, de una garantía de que la facultad regia de negar la sanción sólo sería ejercida razonablemente y nunca por imposición arbitraria del rey ${ }^{61}$.

Por desgracia su vigencia sería breve pues, como es bien conocido, el 4 de mayo de 1814 Fernando VII declaró nula toda la obra de los constituyentes de Cádiz. Es de destacar que, pese a lo fugaz de esta primera etapa liberal, la referida Corporación desarrolló una gran actividad. En concreto, se reunió doscientos noventa y un veces en sesión ordinaria y veintidós ocasiones con carácter extraordinario, examinando un total de unos seiscientos expedientes, de los cuales destacaron por su número los de Gracia y Justicia ${ }^{62}$.

58 "Creo que el artículo no debe variarse de modo alguno, porque los términos en que está extendido comprenden todo cuanto el señor preopinante quiere que se exprese. No es posible atribuir al Consejo de Estado una inspeccion sobre todo lo gubernativo de que atendia el Consejo Real, porque ya V.M. ha aprobado el establecimiento de un Ministerio titulado sobre la Gobernacion del Reino, á cuyo cargo correrán muchos de los asuntos que el Sr. preopinante quiere atribuir al Consejo de Estado, y esto no podría hacerse sin notable atraso en el despacho de los negocios. Tampoco es admisible que el Rey haya de pedir el dictámen del Consejo en todos los asuntos, y sí únicamente en los asuntos graves de cualquiera naturaleza que sean. Lo demás seria coartar tanto las facultades del Rey que vendria á quedar nulo, (...)”, DSC, 31.10.1811, $\mathrm{n}^{\circ}$ 394, p. 2186.

59 Recogen José $\mathrm{M}^{\mathrm{a}}$ Cordero Torres El Consejo de Estado. Su trayectoria y perspectivas, op. cit., p. 6 y Martín Oviedo, El Consejo de Estado durante el régimen constitucional (1808-1812), op.cit., documento anexo $\mathrm{n}^{\circ} 11$, los cambios realizados por los diputados, entre los que destaca el referido logro de Aner consistente en que la propuesta de consejeros se hiciera por las Cortes y no por una Comisión de ellas.

60 Coincidimos, en este punto, con Tomás De La Quadra-Salcedo, "El Consejo de Estado en las Constituciones de Cádiz y Bayona”, op.cit., p. 80. De la misma forma, comparte esta opinión Fernándo Martínez Perez, "De la función consultiva y el Consejo de Estado gaditanos”, Historia Contemporanea, $\mathrm{n}^{\circ} 33,2006$, pp. 568-569.

61 Francisco Tomás y Valiente, “El Consejo de Estado en la Constitución de 1812”, op.cit, p 14.

62 Ricardo Gómez Rivero, El Primer Consejo de Estado Constitucional, 1812-1814, op.cit., p. 17. 


\section{EL RESTABLECIMIENTO DEL CONSEJO GADITANO.}

La sublevación del Riego y de Quiroga en 1820 permitió la vuelta al Constitucionalismo y el restablecimiento de todas las Instituciones liberales. En este sentido, el 18 de marzo de ese mismo año, Fernando VII hacía público el siguiente comunicado:

“Con arreglo al Capítulo $7^{\circ}$ título $4^{\circ}$ de la Constitución política de la Monarquía, se ha servido S.M. resolver se reuna el Consejo de Estado en la forma constitucional que tenia. Lo que comunico á V.S. para su inteligencia y gobierno como uno de los Secretarios del Consejo, según aquella planta. Dios guarde á V.S. muchos años. Palacio 18 de Marzo de 1820 (...)"63.

Una vez más, nadie cuestionó en el seno de las Cortes la necesaria presencia de esta Corporación en el organigrama administrativo. Todas las intervenciones que se hicieron incluían una visión enaltecedora de la misma, como se desprende de la intervención de Moreno Guerra, que la conceptuaba como el contrapeso entre los poderes legislativo y ejecutivo, ${ }^{64}$ o de lo manifestado por Pérez Costa, al afirmar:

"Es sobradamente notorio que el Consejo de Estado es el timon de la nave del gobierno, el sostén del sistema constitucional y de la libertad nacional así como puede ser el instrumento insensible de la esclavitud: es la fuerza media entre los poderes legislativo y ejecutivo, y el equilibrio de ambos, es en suma el alma de todo, y todo cuanto no se oculta á la penetracion y sabiduría del Congreso, siendo preciso por lo mismo un don celestial para la eleccion de sus individuos, en quienes deben resplandecer las virtudes de la sabiduria, fortaleza, patriotismo y otras infinitas de tan dificil hallazgo y reunion (...)"65

Tres días después del mensaje del monarca se verificó la reunión del supremo Cuerpo consultivo ${ }^{66}$, compuesto de los veinte vocales que lo fueron en la

63 En Julián Ma Rubio y Esteban, El Consejo de Estado. Su organización y política en el segundo periodo constitucional. 1820-1823, H.D. Tjeenk Willink \& Zoon, Haarlem, 1925, p. 59.

64 DSC, 24.08.1820, n 51, p. 637.

65 DSC, 25.08.1820, nº 52, p. 650.

$66 \mathrm{Al}$ respecto se publicaba por el diario El censor, el siguiente número: "Si es que tiene usted pensado venirse una temporada á Madrid, véngase cuanto antes, porque es cosa de alquilar balcones, para ver y oir lo que está psando sobre las propuestas y provision de las plazas del consejo de Estado. Nunca, ya se lo aseguro á usted, nunca aparece mas grande nuestra nacion, que cuando se trata de presentar en primera fila los ilustres personages que se destinan á ocupar estos altos empleos. Vive Dios que es mucho apuro para el gobierno hallarse con una porcion de ternas, en las cuales no hay ni siquiera un individuo de estos que se llaman de desecho. Cada dia me convenzo mas de la certeza de nuestros antiguos refranes, al ver lo bien que cuadra ahora aquel que dice: que al que le dan en que escoger, le dan en qué entender. Pues si bien se considera, no solo entre los propuestos, mas ni entre los candidatos, hay uno que no merezca cinco ó seis plazas él solo. = Ha querido la desgracia que no se haya acordado por ahora mas que la provision de catorce vacantes, dejando las otras diez para la proxima legislatura; y esto es lo que nos tiene á todos apusadumbrados y mohinos, al ver que por mas que se haga, no es posible premiar tanta multitud de servicios, ni aprovechar tantos y tan consumados talentos como se presentan en la arena. Yo no he podido haber á las manos, sino una lista de trescientos aspirantes, y en verdad que no quisiera que me diesen el encargo de entresacar solo catorce, porque me veria en calzas prietas para desechar á ninguno. Tan beneméritos me parecen los jóvenes, como los ancianos, los militares como los clérigos, los diplomáticos como los golillas, y los grandes, como los del estado llano. Cada nombre que se va leyendo, le recuerda á uno alguna accion heróica, alguna obra bien 
etapa gaditana. Para que la misma se verificase se habilitó, de forma provisional, una sala del Palacio Real donde se celebrarian sus sesiones. Sin embargo, aun restaba la provisión de las plazas que quedaron sin ser ocupadas en 1812. E1 diputado Moreno Guerra lo pedía ya el 21 de julio:

“(...), pues un Consejo de Estado completo y bueno podrá aconsejar al Rey sobre la sancion de las leyes, y para proponer á S.M. buenos Obispos, buenos magistrados y buenos funcionarios públicos, es el complemento de la Constitucion y superior á las dos Cámaras de que tanto se ha hablado y habla todavia por los que quieren la Constitucion á la extranjera (...) no hay duda de que nombrada parte de sus individuos, deben nombrarse los demás; porque en nombrando uno, es necesario nombrar hasta los 40 que señala la Constitución (...)"67.

No obstante, la votación no comenzó hasta el 25 de octubre, realizándose en sesiones secretas ${ }^{68}$. La tardanza se debe a que existía una cuestión previa por

escrita, alguna virtud sublime, ó por lo menos, una larga carrera de servicios, sin haber dado en ella la menor caida ni tropezon. (...) ¡Oh dichosa España y siglo venturoso en que por mas vacantes que se imaginen, y por mas dificles que sean los encargos que se haya de desempeñar, se encuentran centenares de pretendientes, entre los cuales se puede escoger, como entre peras, sin riesgo de que el elegido valga dos dedos mas que el que fuere desechado! (...)", El censor, periódico político y literario, Madrid, $\mathrm{N}^{\circ}$. 14, sábado 4 de noviembre de 1820 .

67 La proposición se leyó en DSC, 24.08.1820, nº 51, p. 637.

68 En sesión secreta de 3 de noviembre de 1820 se presentaron las propuestas, en lista triple, que había redactado la Secretaría para las plazas vacantes del Consejo de Estado y para las que debían proveerse por primera vez. Se hallaban vacantes dos plazas en la Clase de Grandes de España por fallecimiento de los Marqueses de Astorga y Castelar, y otras dos de particulares por salida de D. Juan Perez Villamil, europeo, y por muerte de D. José Baquijano, natural de Ultramar. Para cubrirlas, propusieron las Cortes a los siguientes sujetos:

"PRIMERA PLAZA EN LA CLASE DE GRANDES DE ESPAÑA.

Sres. Gayoso, Conde de Oñate, Principe de Anglona.

SEGUNDA PLAZA EN LA MISMA CLASE

Sres. Duque de Frias. Duque de Noblejas. Duque de Pinohermoso.

TERCERA PLAZA DE EUROPEOS.

Sres Porcel. Conde de Taboada. Jáuregui

CUARTA PLAZA DE NATURALES DE ULTRAMAR

Sres. Terán. Velazquez de Leon. Marqués de San Francisco de Herrera"

En cuanto a la propuesta dirigida a las plazas que se proveían en ese momento por primera vez, eran 10: una de la clase de Obispos, una en la de Grandes de España, cinco en la de particulares y europeos y tres en la de naturales de ultramar. La lista era la siguiente:

“CLASE DE OBISPOS:

El de la Habana. El de Segorbe. El de Tuy.

CLASE DE GRANDES:

Sres Marqués de Cerralbo; Marqués de Santa Cruz; Marqués de Villafranca.

CLASE DE PARTICULARES

Europeos:

Sres. Vigodet, Ballesteros, Baron de Castellet. Quintana. Pezuela, Bustos, La Serna, Valdemoros, Zumalacárregui, Acevedo, Alonso, Torres, Cano Manuel, Carvajal, Venegas. 
resolver. Lo expresaba por aquel entonces Romero Alpuente, para quien era necesario determinar, por un lado, el número de individuos que habria de designarse -esto es, si los cuarenta o sólo veinte como en el período de 1812- y, por otro, si podían conservar su cargo los consejeros del bienio 1812-1814 o, por el contrario, debía renovarse por completo la referida institución ${ }^{69}$. Para resolver esta cuestión se nombró una comisión encargada de dar respuesta a la incógnita. Sin embargo, no se privaron algunos de los parlamentarios de mostrar sus consideraciones con carácter previo a conocer su dictamen. Así, el Conde de Toreno manifestó, de forma terminante, que debía completarse el número de componentes, no dejando plaza vacante ${ }^{70}$. Castañedo, por su parte, entendía que los miembros de la referida Corporación eran "interinos", por lo que debía elegirse a la totalidad de los mismos, quedando relegados de sus cargos aquellos que los ocuparon en la etapa gaditana ${ }^{71}$. De acuerdo con este diputado se mostró Perez Costa, quien intervino alegando que en 1814 el Consejo de Estado fue declarado nulo y, en este sentido, fueron despojados de sus puestos los sujetos que lo componían. De esta forma, era legítimo pensar que en 1820 los integrantes del Cuerpo consultivo habian sido reestablecidos de forma provisional. Por lo tanto, no podía permitirse que estos continuasen en sus funciones sin haber sido reelegidos. Más aún si se tenía en cuenta que los actuales miembros no contaban con el requisito de ser seleccionados por el monarca y que dichos sujetos podian haber observado en los últimos seis años de opresión una conducta política cuestionable ${ }^{72}$. Por esta razón, solicitaba a la comisión que aclarase en su dictamen:

“ $1^{\circ}$. Si se debe declarar solemnemente que no existe Consejo de Estado en propiedad.

\section{De Ultramar:} 33.

Lardizábal, Luyando, Arango, Aróstegui, Ortiz, Palacios, O-Farril, Viola”, DSC, 03.11.1820, p.

69 “(...) lo que hay que resolver es: primero, si deberán nombrarse los 40, porque la falta de recursos nos pone en estado de economizar los sueldos: segundo, si se nombrarán solo 20: tercero, si este número será suficiente; y en este caso, si continuarán los actuales consejeros, porque aunque no tienen nombramiento del Rey, acaso no podrán removerse (...). Así apoyo que se nombre una comision; pero no para que proponga las listas, sino para que presente su dictámen sobre todas estas dudas.", DSC, 24.08.1820, nº 51, p. 637.

70 DSC, 24.08.1820, n 51, p. 637.

71 DSC, 24.08.1820, nº 51, p. 637.

72 "Las fatales ocurrencias del año de 14, que han trastornado todo el sistema constitucional, dejaron nulo el Consejo de Estado, establecido por las Córtes generales y extraordinarias, y despojados de este derecho á los individuos que lo componian, como á los Sres Diputados de las ordinarias de la representacion y autoridad que estaban ejerciendo; y así como éstos, felizmente restablecida la Constitución, no han continuado en sus funciones, y se han elegido nuevos Diputados para las presentes Córtes de los años 20 y 21, parece que aquellos se hallan en el mismo caso; y así debe creerse ser el dictámen del Rey, por el hecho de haberlos restablecido solo en clase de interinos (...) Por el capítulo VII de la Constitucion tiene el Rey el derecho de elegir uno de cada terna que las Córtes le presenten para consejero de Estado, cuya facultad no ha ejercido S.M., y se hallaban y hallan sin este preciso y constitucional requisito los referidos consejeros nombrados en el año de 1812 por las Córtes, despojado el de 14 y reintegrados el de 20 por el Rey solo interinamente (...) el Consejo perdió su existencia. Su actual ejercicio es solo interino y provisional (...)", DSC, 25.08.1820, n 52, pp. 649-650. 
$2^{\circ} \mathrm{Si}$ consiguientemente deberán las Córtes formarlo nuevamente en su totalidad con arreglo á la Constitucion.

$3^{\circ}$. Que en este caso aquellas, conforme á ésta, propongan las listas triples al Rey, pudiendo ser comprendidos en ellas todos, parto ó ninguno de los actuales consejeros interinos."73

No fueron, sin embargo, de esta opinión los diputados Espiga, Villanueva, Muñoz Torrero o Banqueri ${ }^{74}$, que defendieron que no podía considerarse provisional al nombramiento, sino sólo al número seleccionado de individuos ${ }^{75}$.

La Comisión presentó su resolución el día 6 de octubre ${ }^{76}$. Respecto al número de consejeros que debía elegirse, atendiendo a la situación existente con las colonias, optó por un término medio y decidió que debían nombrarse solo treinta. Entendía que era aconsejable dejar vacantes algunas plazas que podrian tocar a determinados países "disidentes" de América cuando se reconciliasen con España ${ }^{77}$. A las aclaraciones solicitadas por Pérez Costa, contestó afirmando que los vocales eran propietarios de sus destinos, y esto porque el Consejo de Estado quedó meramente anulado de hecho, pero de derecho existió todo el tiempo. Por lo tanto, no era legítimo calificarles de interinos, ni despojarles del derecho a sus cargos. Mantener lo contrario seria reconocer que la Constitución, las leyes y los decretos de las Cortes fueron anulados, lo que no era admisible en modo alguno. Más aún si se tenía en cuenta que la derogación del texto constitucional se llevó a cabo a través de un acto violento y forzado, que no podía producir efectos jurídicos. Una vez restablecida la Carta Magna, habían de serlo también necesariamente las Instituciones y los nombramientos de los funcionarios que de ellas procedian. Si esto no fuera así, y se reconociese que los individuos de la referida institución habian quedado privados de sus puestos en virtud de aquellos actos ilegales, se aceptaría autoridad y derecho en los que cometieron estas acciones abusivas ${ }^{78}$.

En cuanto a la falta del requisito de designación real, respondió la Comisión que la creación de la referida Corporación y el nombramiento de sus miembros se hizo por las Cortes extraordinarias, en las que residia la soberanía nacional. Por lo tanto, dudar de esta designación, supondría poner en cuestión su poder y declarar inválidas todas las leyes, decretos y cuantas disposiciones fueron

73 DSC, 25.08.1820, no 52, p. 650.

74 Este último se manifestó en oposición al Sr. Perez Costa el 25 de agosto de 1820, defendiendo que los consejeros de estado existentes eran propietarios desde 1814 y que en 1820 lo único que se había hecho fue reponerlos en sus destinos, DSC, 25.08.1820, n ${ }^{\circ} 52$, p. 650 .

75 Todas las intervenciones en DSC, 24.08.1820, nº 51, pp. 637-638.

76 DSC, 06.10.1820, nº 94, pp.1443-1445.

77 “(...) aconsejando la política que se dejen por ahora vacantes algunas plazas del Consejo de Estado que pudieran tocar á personas de países disidentes si llegaren á reconciliarse con sus hermanos de Europa y la economía que se ahorren, lo más que sea dable, unos sueldos que desde el dia $1^{\circ}$ del año próximo serán cuantiosos si se alzase la ley del máximun (...) la comision es de parecer que en la actualidad solo se nombren hasta el número de 30 consejeros de Estado; término medio entre los 20 que nombraron las Córtes generales y extraordinarias y los 40 que dispone la Constitucion, y que ofrece cómoda division para que proporcionalmente puedan ser tres consejeros eclesiásticos, tres grandes de España y nueve americanos lo menos", DSC, 06.10.1820, no 94, pp.1443-1445.

78 DSC, 06.10.1820, n 94, pp. 1443-1444. 
tomadas siendo necesaria la sanción del rey. Continuaba señalando que, si la pretensión de la total renovación tenía el fundamento de excluir a aquellos individuos que hubiesen devenido en indignos durante los seis años de absolutismo, debía respetarse lo establecido en la Constitución, que mostraba el camino que debía seguirse. Las Cámaras legislativas no estaban autorizadas de forma alguna para enjuiciar, eso excedería sus atribuciones “(...) y en tal caso las Córtes aun harian más que juzgar, pues impondrian á algunos consejeros de Estado la grave pena de privarlos de sus destinos y de su opinion, y esto sin juicio, sin pruebas legales, sin defensas, sin sentencia judicial, y solo por el juicio de nuestras conciencias (...)"79.

Es de destacar que esta decisión no gozó de unanimidad en el seno de la Comisión. Los diputados Gasco y Vadillo formularon sus votos particulares, suscribiendo que los funcionarios públicos nombrados antes de 1814 y repuestos en 1820, con el fin de que no se entorpeciese el curso de los negocios, lo eran en calidad de interinos. Por eso mantenían que se estaba en el caso de proceder a seleccionar de nuevo a todos los consejeros. No podía ser de otra manera, pues así se habia hecho con las Diputaciones Provinciales, los Ayuntamientos e, incluso, con las propias Cortes ${ }^{80}$. Esta opinión era la sostenida por parte de la opinión pública. De esta forma, el diario Miscelanea de comercio, politica $y$ literatura, recordaba que los decretos de las Cortes exigian que para alcanzar los distintos destinos públicos, era requisito indispensable el probar la adhesión al régimen constitucional. No tenía sentido, por tanto, en opinión del editor, que se obviase dicha exigencia en el caso de los consejeros ${ }^{81}$.

Tras la lectura del dictamen de la Comisión, se señaló el 12 de octubre para su discusión, si bien la misma se llevó a cabo los días $16^{82}$, en sesión extraordinaria, y 1783. La mayor parte del Hemiciclo se mostró conforme con el

79 DSC, 06.10.1820, nº 94, p. 1445.

80 “(...) los que suscriben no pueden menos de opinar como la Junta consultiva acerca del carácter provisional que asiste á los funcionarios públicos nombrados antes de dicho mes de Mayo de 1814, y repuestos en Marzo de 1820 con el único fin de que ni por un instante se entorpeciese el curso de los negocios en el sistema constitucional. Esta regla no solo la adoptó prudentemente el Gobierno respecto á los empleados de su libre nombramiento y remocion, sino que se aplicó á las Diputaciones provinciales y á los ayuntamientos nombrados por los pueblos, y á las Juntas de Censura, cuyos vocales nombrados por las Córtes han sido ahora ó confirmados ó subrogados por otros diversos. Ni parece que pudiera ó debiera ser otra cosa, cuando la utilidad pública ha exigido que se procediese para las presentes Córtes á nuevas elecciones de Diputados (...)", DSC, 06.10.1820, n 94, p. 1445.

81 "Los decretos de las córtes ordinarias previenen que para obtener los destinos, precedan pruebas nada equivocas de la adhesion de los antiguos magistrados y funcionarios públicos al sistema institucional. ¿Cómo pudiera dejar de aplicarse esta disposicion á los consejeros de estado? Yo no se por otra parte como pueda mirarse esto como una pena, y mas cuando no se ha mirado como tal el que los diputados del año 14 no hayan completado el tiempo de su diputacion. Si la representacion nacional no ha sido organizada con los mismos individuos que tenia en aquella época ¿por qué ha de ser de mejor condicion el consejo de estado? La intencion del gobierno fue solo de reponer los consejeros de estado interinamente, y todas sus medidas muestran que no quiso darles otro carácter", Miscelanea de comercio, politica y literatura, $\mathrm{N}^{\circ} 232$, miércoles, 18 de octubre de 1820 .

82 DSC, 16.10.1820, nº 104, pp. 1679-1694.

83 DSC, 17.10.1820, nº 105, pp. 1695-1713. 
dictamen de la Comisión84. En su defensa, sostenían que declarar a los consejeros vacantes de sus destinos supondría llevar a cabo actos contrarios a derecho, pues sus nombramientos fueron totalmente legítimos. En este punto, entendian que, tanto la disolución del Consejo de Estado, como la separación de sus miembros fue antijurídica ${ }^{85}$. Aunque admitían que el texto constitucional requeria que sus integrantes fuesen elegidos por el rey, señalaban que este requisito solo debía ser exigible a aquellos nombramientos realizados con posterioridad a la publicación de la Constitución. Por lo tanto, los actuales componentes no podian verse afectados por esta prescripción. De esta forma, la falta de designación real no era argumento oponible a la consideración de éstos como propietarios de sus $\operatorname{cargos}^{86}$. A lo manifestado añadian que las referidas designaciones tenían la confirmación del rey pues, nueve días después de jurar la Constitución en 1820, expidió un decreto en el que se convocaba el Consejo de Estado con la misma composición que había tenido hasta 181487 . Si lo que se

84 En concreto, se mostraron favorables los diputados Marcial López, Silves, Zapata, Rey, Cortés, Dolarea, Calderon, Victorica y Moragues.

85 Este argumento fue el utilizado, entre otros, por el diputado Cortés, decía: “(...) Es preciso sentar por base de mi discurso que los actuales consejeros de Estado fueron elegidos en propiedad por las Córtes generales y extraordinarias. Nada faltó en aquella eleccion para que tuviera la calidad de permanente y perpétua. Aquellas Córtes podian hacerlo así: ellas reunian todo el poder de la soberanía de que las había revestido la Nacion; y aunque es cierto que habia un Consejo de Regencia que desempeñaba el cargo del Poder ejecutivo, éste no obraba sino en comision, y era amovible; lo que no sucede con un poder constitucional, que lleva consigo el carácter de inamovilidad. (...)= Ahora bien: si los consejeros fueron propietarios hasta Mayo del año 14, ¿quién les privó de esta propiedad? ¿Seria por ventura aquel golpe de autoridad que sepultó al Consejo de Estado juntamente con todas las instituciones constitucionales? ¿Y se querrá ahora en estos felices dias tener por válido y legítimo cuanto se hizo entonces con las armas? La fuerza no es capaz de anular un derecho, ni de prescribir contra las naciones que la sufren, ni contra sus individuos, los cuales habitualmente están protestando contra ella y aspirando cuanto pueden al recobro de sus derechos. Si hubiera sido válido y legítimo aquel acto para sepultar de derecho al Consejo de Estado, lo hubiera sido igualmente para anular la Constitucion; y si esto pudiera ni aun imaginarse, ahora mismo nos hallariamos sin Constitucion, pues estas Córtes en que estamos reunidos no son seguramente Córtes Constituyentes", DSC, 16.10.1820, no 104 , pp. 1690-1691.

86 Este punto era defendido, en concreto, por Silves. Al respecto señalaba: “¿Faltó acaso en las Córtes la autoridad suficiente para darles perpetuidad, ó quedó ésta en suspenso hasta que recayese la aprobación ó confirmación del Rey? ¿Quién sabia entonces, ni probablemente podia calcular cuándo llegaria el caso de que el Rey pudiera darla? Se estaban proveyendo en perpetuidad empleos de judicatura y otros que por su naturaleza la tienen, ¿y solo los más altos, los más importantes se habian de dejar inciertos y dependientes de un caso tan remoto y contingente? En la Constitucion se prevenia que los consejeros de Estado habian de ser nombrados por el Rey á propuesta de las Córtes; pero antes de publicarla, y aun de acabar de sancionarse, es decir, antes que fuese ley, acordaron crear previamente el Consejo de Estado, y elegir por si mismas por aquella vez los 20 individuos de que por entonces se habian de componer. Obvio, pues, y muy fácil es de conocer que la necesidad de la elección ó nombramiento del Rey, que se establecia en la Constitucion, no había de ser para un nombramiento hecho ya con anterioridad á su publicación, sino para los que se hubiesen de hacer en lo sucesivo, y cuando restituido el Rey en su trono estuviese en disposición de hacerlo.", DSC, 16.10.1820, ${ }^{\circ}$ 104 , p. 1681.

87 Así lo señalaba Silves: "Pero es el caso que si los consejeros de Estado hubiesen necesitado la aprobacion ó confirmacion del Rey, la tienen hoy expresa, terminante y repetida. Nueve dias despues de haber jurado la Constitucion expidió un decreto, que se anunció en Gaceta extraordinaria, y en que dijo S.M. que con arreglo á lo dispuesto en el capítulo VII, título IV de ella, había venido en resolver se reuniese el Consejo de Estado, cuya asistencia era necesaria para las determinaciones que exigia el buen gobierno de los pueblos, debiendo componerse de D. 
pretendía era separar a aquellos individuos de conducta cuestionable, tenía que hacerse respetando los artículos 239 y 243 de la Constitución, según los cuales, los consejeros debian ser juzgados por el Tribunal Supremo para poder ser removidos. Si las Cortes ignoraban estos dos preceptos y separasen por si mismas a los referidos sujetos, obrarian de forma ilegal y anticonstitucional, y atentarían contra la división de los poderes, contra la Constitución y contra la libertad $^{88}$.

Los contrarios al dictámen de la Comisión ${ }^{89}$, por su parte, expresaban su convencimiento de que el decreto de 1820 no incluía referencia alguna a las características del cargo. En este sentido, no podía considerarse un documento válido para interpretar la verdadera intencionalidad del rey a la hora de configurar a este destino como provisional o definitivo. Esta voluntad debía buscarse, a su parecer, en el hecho de que la reunión del Consejo de Estado se había realizado conforme al dictamen de la Junta provisional, que había opinado por la temporalidad del mismo ${ }^{90}$.

A este argumento añadian el consistente en que todos los funcionarios públicos nombrados antes de 1814 fueron repuestos en sus cargos de forma interina, no debiendo hacerse excepciones. Advertian del peligro de considerar a los consejeros propietarios de sus puestos, puesto que muchos de los que antes

Joaquin Blake, decano, D. Pedro Agar, etc.; nombrándolos por el mismo órden con que lo estaba en el decreto de las Córtes (...) yo no encuentro palabra, expresion ni indicacion alguna que respire semejante interinidad. El Rey llamó á los consejeros que estaban nombrados en el decreto de las Córtes; y si en él lo estaban con perpetuidad, con la misma los llamó, aprobó y confirmó, puesto que no expresó lo contrario. Con el mismo decreto se convocó á todos los ausentes y presentes: unos y otros se han ido presentando sucesivamente, y á todos les ha recibido S.M. por sí mismo el juramento. ¿No serán, pues, otros tantos actos de confirmacion y aprobacion cuantos juramentos han prestado en sus Reales manos?”, DSC, 16.10.1820, n 104, p. 1681.

88 Este argumento fue utilizado por los diputados Marcial López, Silves, Rey, Dolarea y Moragues. Transcribimos aquí, por su especial elocuencia, el discurso de Dolarea: “(...) E1 consejero de Estado, como otro cualquiera empleado, puede ser criminal, pues es hombre, y capaz por consiguiente de ser indigno del puesto que ocupa, por crimenes cometidos despues del nombramiento: mas lo que esto quiere decir es que la ley bajo cuyo imperio vive, puede y debe quitar el empleo, si observando los trámites que prescribe en juicio formal, y con audiencia del mismo, falla definitivamente su deposicion ó privacion. Pregunto yo ahora: ¿estamos en este caso? La Constitucion, decretos de las Córtes y leyes vigentes ¿autorizan en el momento esta medida? De ningun modo: antes todas les conservan el carácter de propiedad y libertad individual y politica hasta que se hallen calificados de reos por sentencia definitiva. (...) El art. 239 de la Constitucion dice que los consejeros de Estado no podrán ser removidos sin causa justificada ante el Tribunal Supremo de Justicia (...) ¿Cómo, pues, sin observar esos trámites esenciales de la justicia puede sin formárseles causa y fallar definitivamente contra ellos, privarles ó suspenderles de la propiedad de sus destinos?", DSC, 17.10.1820, n 105, p. 1708.

89 Éstos fueron, entre otros, los diputados Gasco, Vadillo y Felipe Navarro.

90 De esta forma se expresaba, en concreto, el diputado Vadillo. Decía: "Se ha dicho tambien que el restablecimiento en sus destinos de los consejeros de Estado no ha sido provisional, pues que en el decreto expedido para su reunion nada se dice de interinidad, como en todos los demás relativos á otros empleados que al principio de nuestra regeneracion despachó el Rey para reorganizar el sistema constitucional. Aunque es cierto que en el decreto expedido por S.M. para la reunion del Consejo de Estado nada se dice de interinidad de los consejeros, tambien lo es que se guarda el mismo silencio sobre la propiedad. El Rey reunió el Consejo de Estado con acuerdo y en conformidad á las consultas de la Junta provisional; y habiendo opinado ésta por la interinidad, es claro que bajo esta calidad se verificó la reunion del Consejo de Estado. (...)", DSC, 16.10.1820, $\mathrm{n}^{\circ} 104$, p. 1685 
de 1814 se mostraron favorables al sistema e Instituciones liberales, habian alterado su carácter y cualidades durante el periodo absolutista, mostrando su desapego al régimen constitucional ${ }^{91}$. El riesgo de que a lo largo de los seis años totalitarios alguno de ellos hubiese realizado actos indignos implicaba que su legitimidad no era clara, debía investigarse ${ }^{92}$. Sólo una vez formado expediente y probada su buena conducta, podrian las Cortes mantenerlos en sus destinos como propietarios ${ }^{93}$.

En una posición intermedia se situaban el Conde de Toreno y Navas. El primero, si bien consideraba a los actuales consejeros de Estado propietarios de sus cargos, entendia que debía exceptuarse a aquellos que hubiesen observado una conducta censurable en los últimos seis años, como la de haber tenido parte en la persecución contra los patriotas que quisieron restablecer el sistema constitucional. La fórmula que proponía para ejecutar esta medida era, según decía, bien sencilla:

“(...) basta recorrer la historia del tiempo. Hubo tal tribunal, entendió en tal causa, era indivíduo de él; pues ya no es consejero de Estado. No es

91 Así lo afirmaba, en concreto, Gasco. Decía: “(...) conocerán las Cortes que la conveniencia pública se interesaba en que la reunion de los consejeros de Estado fuese interina y provisional, porque el período de seis años que habia corrido desde el decreto de 4 de Mayo de 1814 hasta el fausto dia de 7 de Marzo último, en que juró interinamente S.M. la ley fundamental que felizmente nos rige, podia haber causado, y con efecto ha producido tal mudanza y variacion en el carácter y cualidades de las personas, que muchas de ellas, adictas y decididas en tiempos anteriores por el sistema é instituciones liberales, dieron en el tiempo que ha mediado desde uno á otro período constitucional pruebas perentorias y convincentes de inhadesion, desafecto y aun ódio (...)" , DSC, 16.10.1820, n 104 , p. 1684.

92 Defendia este punto Vadillo. Afirmaba: “(...) no sé yo por qué hayamos de salir de la regla general prudentemente adoptada cuando el Rey juró la Constitucion, respecto á todos los funcionarios públicos nombrados con arreglo al Código fundamental de la Monarquía, desde su solemne promulgacion hasta el aciago dia de 10 de Mayo de 1814. La regla general fué la reposicion interina de dichos funcionarios, que es de la que ahora se trata, pues nunca ha ocurrido á los dos que hemos disentido del dictámen de la mayoría de la comision, el disputar que los consejeros de Estado lo fuesen en propiedad cuanto las Córtes los nombraron en 1812, y todo el tiempo que desempeñaron sus funciones mientras subsistió el sistema constitucional. (...) previendo que en el intermedio fatal de los últimos seis desgraciados años podria haber algunos que hubiesen desmerecido de la reputacion que antes obtuvieron, quiso el Gobierno con sumo tino y discrecion reservarse el tomar noticias oportunas acerca de ellos, sin perjuicio de subvenir á la necesidad del momento, proveyendo á los pueblos de las autoridades indispensables en el nuevo régimen con personas que le habian sido adictas cuando se hallaba vigente y contra cuya conducta posterior nada habia aparecido de pronto (...)”, DSC, 16.10.1820, n 104, p. 1691-1692.

93 Este fue el argumento sostenido, entre otros, por Romero Alpuente, quien manifestaba: “(...) entren á sus destinos los consejeros que habia; pero para que no traiga consecuencias irreparables esta medida aconsejada por la necesidad, digamos que son interinos, porque su derecho no está claro, y esta duda no la podemos nosotros resolver, ni el Rey tampoco. ¿Quién, pues ha de resolverla? Las Córtes. He aqui la razon de venir ahora este expediente al Congreso ¿Y viene para que el Poder judicial le determine, como se ha querido suponer? ¡Que ha de venir, Señor para eso, no correspondiendo á las Córtes sino el poder legislativo! Viene para que ejerciendo este poder declaren que son interinos, y sean lo que fueren, manden que no pudiendo la Constitucion haber tenido presente estos seis años, ni los papeles representados en ellos por algunos de sus consejeros, se mantenga en sus destinos á los que, no segun una causa interminable, sino segun un expediente instructivo, no los hayan desmerecido (...) si hay en él uno siquiera de cuyo patriotismo y virtudes patrióticas se dude, está en la alta política buscar un temperamento por donde se eviten las consecuencias y dilaciones de un juicio (...)", DSC, 16.10.1820, no 104 , pp. 1693-1694. 
menester para esto un expediente judicial, sino administrativo; á un expediente judicial me opondría siempre, porque nunca acabariamos, y harto llevamos con seis años de revolucion: para lo que propongo no hay necesidad de más que una mera aplicacion de la ley de las Córtes" 94.

El segundo, por su parte, proponía que conservasen su derecho sólo aquellos que no hubiesen aceptado un destino incompatible con el mismo durante el período absolutista, pues esto supondría haber renunciado a él ${ }^{95}$.

Especialmente interesante es la intervención de Zapata, pues fue, junto a Felipe Navarro ${ }^{96}$, el único que cuestionó la decisión de la Comisión por la que señalaba en treinta el número de consejeros, reclamando se elevase a cuarenta ${ }^{97}$. Fundamentaba su desacuerdo, por un lado, en que se trataba del único Cuerpo intermedio entre el monarca y la representación nacional, y, por otro, en las serias funciones atribuidas a este órgano, sin que a su parecer sirviese de justificación que en 1820 se eligiesen solo veinte miembros ${ }^{98}$. Sus palabras resultan especialmente elocuentes:

94 DSC, 17.10.1820, n⿳ 105, pp. 1687-1688.

95 “(...) No puedo convenir con lo que acaba de decir el Sr. Victorica, dando por supuesto que todos convienen en que son propietarios. Lo que han afirmado varios señores preopinantes, y yo creo está probado, es que fueron propietarios. Resta ahora saber si lo son en el dia; y yo voy á demostrar que unos lo son y otros no. No convengo tampoco con el principio establecido por el Sr. Navarro, de que en el año 14 todo se anonadó y abismó, y todo el Consejo cesó en el derecho y en el hecho. En el hecho está bien; pero no en el derecho. El derecho de la Nacion es imprescriptible, (...) nada importa averiguar si pasaron tres, cuatro ó cinco años; para el caso lo mismo son horas que años. Ahora bien: nadie dudará que si despues del 10 de Mayo del año 14, en que todo se echó abajo, se hubiese restablecido á las veinticuatro horas el sistema constitucional, los consejeros hubieran conservado su derecho y hubieran vuelto á ocupar sus plazas en propiedad, sin que les perjudicase tan corta interrupción. (...) Digo, pues, ahora, que todos los que no hayan renunciado, vendido ó permutado este derecho, le conservan (...) ¿Cómo se pierde el derecho de una plaza ó empleo? (...) En el momento en que se admite otro destino incompatible con el que se tenia anteriormente. Este es un principio de justicia que se observa en la práctica. (...) luego es claro que estos son interinos en el Consejo de Estado. No es lo mismo respecto á los que no han tenido otros empleos, y que jamás han enajenado su derecho: estos son propietarios, porque nunca han perdido el derecho que adquirieron cuando tomaron la plaza de consejeros (...)”, DSC, 17.10.1820, n⿳0 105, pp. 1709-1710.

96 “Tengo muchísima repugnancia á conformarme con el dictámen de la comision acerca del número de los que deben nombrarse nuevamente para el dicho Consejo. La Constitucion politica previene literalmente se componga el Consejo de Estado de 40 indivíduos, y yo no encuentro motivo ninguno para que esto deje de observarse religiosamente (...) Es muy justo esté completo el cuerpo que sirve de mediador entre el Poder legislativo y el ejecutivo; el único que puede dar funcionarios dignos al Poder judicial y al culto, y el que por medio de su sabiduria puede ilustrar al Rey en el camino del acierto y de la felicidad. Disiento en consecuencia del dictámen de la comision, en cuanto separándose ésta de lo que la Constitucion previene, reduce á 30 por ahora las personas de que se ha de componer el Consejo de Estado", DSC, 17.10.1820, n 105 , pp. 1706-1707.

97 Tanto el Conde de Toreno como Cortés manifestaron expresamente que era una cuestión subalterna o secundaria que dejaban a elección de las Cortes.

98 “(...)no veo la causa por qué la comision señala el número de 30. La Constitucion previene que habrá un Consejo de Estado, y que éste se compondrá de 40 indivíduos. A la verdad, son muy altas y del mayor interés las atribuciones de este cuerpo. (...) Por eso exige la Constitucion que sea numeroso este cuerpo. No es obstáculo para ello el que las Córtes extraordinarias eligiesen solo el número de 20: entonces no estábamos en relacion con todas las provincias; el Rey se hallaba cautivo, y las Córtes sin duda quisieron dejar á su eleccion la de los 20 restantes, presentados en el modo y forma que ha prevenido la Constitución (...) las Córtes, en mi opinion, no deben diferir 
“(...) si no completamos ahora el número de los 40, ¿no haríamos una injusticia á la España europea privándola del número que le corresponde por el solo motivo de que aun hay disidentes en América? ¿No serían perjudicados igualmente los que en estas provincias han permanecido fieles y en union con su madre Pátria? ¡Y quién sabe si el no completar ahora el Consejo daria nuevas armas á la cavilosidad é injusticia de algunos que osarian atribuir á fines siniestros esta reserva en el nombramiento!"99

En la sesión ordinaria del 17 de octubre se procedió a la votación del dictamen de la Comisión por partes, y todas fueron aprobadas ${ }^{100}$. No estuvo esta votación, sin embargo, libre de votos particulares, y en concreto los de Arendo y Quintana, contrarios a la declaración de propiedad en el cargo de los componentes del Consejo de Estado, y los de Florez Estrada y Desprat, opuestos a todos y cada uno de los extremos que habian sido ratificados ${ }^{101}$.

Resultaron, sin embargo, estériles dichos debates. El 7 de abril de 1823 el país se vio invadido de nuevo por un ejército francés. El decreto de 1 de octubre de 1823 restauraba el absolutismo y convertía en fugaz la duración de este Consejo ${ }^{102}$, al declarar nulos y de ningún valor todos los actos del gobierno constitucional.

Sin embargo, en nuestra opinión, el examen del diario de sesiones pone de manifiesto cómo, pese al transcurso del tiempo y a la evolución y cambios ideológicos que éste siempre lleva aparejado, se siguió manteniendo la consideración de que el Consejo de Estado era una Institución imprescindible en la Administración española. Como hemos tenido ocasión de ver, ni los debates parlamentarios ni los distintos periódicos cuestionaron su reinstauración, sino que, al contrario, exigieron cuanto antes su arreglo.

\section{EL CONSEJO DE ESTADO DURANTE LA REGENCIA DE MARÍA CRISTINA.}

Como es bien sabido, el fallecimiento de Fernando VII en 1833 supuso la ruptura definitiva del país con el Antiguo Régimen. Durante la Regencia de María Cristina se vivió una auténtica fiebre de reformas ${ }^{103}$ llevadas a cabo en distintas

el completar su número, para que tenga entonces toda la fuerza de que es susceptible, y para que sus deliberaciones presenten toda la ilustracion y vigor que en vano se desearian de un corto número de individuos, por más atinada que fuese su eleccion(...).”, DSC, 16.10.1820, n 104 , pp. 1686.

99 DSC, 16.10.1820, no 104, p. 1686.

100 DSC, 17.10.1820, no 105 , p. 1712 .

101 DSC, 17.10.1820, no 105 , p. 1723.

102 Imprescindibles para conocer la actuación del Consejo en este período histórico resultan las monografias de Ricardo Gómez Rivero: Los Magistrados del Primer Constitucionalismo, Thomson Aranzadi, 2009, donde se "estudian los trámites de nombramiento de los ministros de las Audiencias, en los que se incluyen los informes (...), las votaciones del Consejo de Estado-tanto las destinadas a señalar quiénes debian permanecer en sus puestos como las que conformaban las ternas-y la resolución de Fernando VII, que tiene lugar en el despacho que celebra con su ministro de Gracia y Justicia"; y Las elecciones municipales en el Trienio Liberal, Boletín Oficial del Estado, Madrid, 2015, que analiza aquellos expedientes relativos a elecciones municipales que el Ministro de la Gobernación pasaba a dictamen del Consejo de Estado.

103 Alejandro Nieto, "Apuntes para una historia de los autores de Derecho Administrativo general Español”, en Alejandro Nieto (edit.), 34 artículos seleccionados de la revista de la Administración 
Instituciones de gobierno como los Consejos, las Secretarías de Despacho o los Ministerios ${ }^{104}$.

El 24 de marzo se publicaron seis decretos que extinguieron los viejos Consejos y articularon una nueva planta administrativa. En concreto, y en lo que aquí nos atañe, se encargaron de instaurar el Consejo Real de España e Indias, dejando en estado de hibernación al de Estado gaditano hasta que la reina Isabel alcanzase la mayoria de edad. La justificación venía dada en el hecho de que el finado monarca había ordenado en su testamento la instauración de un Consejo de Gobierno destinado a ser consultado por la regente en los negocios más arduos, quedando sin sentido la existencia de otro órgano consultivo ${ }^{105}$.

No duró mucho, sin embargo, esta ordenación. En 1836 los acontecimientos del palacio de la granja obligaron a $\mathrm{M}^{\mathrm{a}}$ Cristina a restablecer la Constitución de 1812. De forma automática, por decreto de 28 de septiembre de 1836106, se suprimió el Consejo Real de España e Indias por considerarlo incompatible con el artículo 236, que establecía que el único Cuerpo consultivo del rey era Consejo de Estado107. Sin embargo, contra todo pronóstico éste último no fue restablecido.

Pública con ocasión de su centenario, Instituto Nacional de la Administración Pública, Madrid, 1983, p. 22.

104 Carmen Losa Contreras, "La administración consultiva en los inicios del Estado Liberal. El funcionamiento del Consejo Real de España e Indias. Sección de lo Interior (1834-1836)", Cuadernos de Historia del Derecho, $\mathrm{n}^{\circ}$ 7, 2000, p. 457.

105 Sobre la Administración Pública en esta etapa histórica puede consultarse la obra de Alejandro Nieto, Los primeros pasos del Estado constitucional. Historia administrativa de la regencia de María Cristina, Ariel, 2006, Barcelona.

106 Gaceta de Madrid, $n^{\circ}$ 658, viernes, 30 de septiembre de 1836.

107 En este sentido, resulta necesario traer a colación la publicación del diario El Castellano, Periódico de Politica, Administración y Comercio. De acuerdo con su editor, las funciones de este órgano se solapaban con la de otros entes públicos. Su existencia, por tanto, no conllevaba más que un gasto innecesario para el país. Decía: "El código de los 384 artículos no tiene uno por donde pueda presumirse que consiente el llamado Consejo real de España é Indias, que en nuestro concepto nunca fue necesario y siempre perjudicial. Lo primero porque sin él bastan oficinas, cuerpos y empleados para despachar todos los negocios que ocurrir puedan; si corresponden á la Gobernacion, y el oficial es perezoso, inepto, ó que no quiere, hay ayuntamientos, diputados provinciales, gefes políticos, juntas, direcciones, universidades, y el ministerio, que sobran para ilustrar la materia. Si pertenecen á Gracia y Justicia, hay juzgados de primera instancia, audiencias, tribunal supremo y ministerio. Si son de Hacienda, hay intendentes con no pocas oficinas, direccion general, que es una colmena, superintendencia, contaduria, tribunal supremo y el ministerio. Si es asunto de Guerra, hay capitanias generales, consejos de guerra, comisiones, estados mayores, intendencias, ordenaciones, pagadurias, directores, inspectores, tribunal supremo y ministerio. Lo mismo sucede en el de Estado y Marina; y vamos al segundo, porque la escandalosa suma de los cuantiosos sueldos (segun nuestra situacion) no puede cubrirse con el sudor de diferentes provincias, y no es tiempo de beneficios simples y pingües canogias que ni son precisas ni útiles, como el Consejo real, á la religion ni al estado. Lo indispensable, y economía. Guerra á toda costa; Hacienda sin tanto costo, y tener presente que segun los artículos 8 y 9 de la CONSTITUCION, todo español está obligado, sin distincion alguna, á contribuir en proporcion á sus haberes para los gastos del estado, y á defender la patria con las armas cuando sea llamado por la ley.", El Castellano, Periódico de Política, Administración y Comercio, $\mathrm{n}^{\circ}$ 9, jueves, 18 de agosto de 1836. Prácticamente lo mismo se decía por el periódico Eco del Comercio, según el cual: "El consejo real era un cuerpo monstruoso, que ademas de los muchos vocales tenia ocho secretarisa, ocho secretarios con buena dotacion cada uno de oficiales, escribientes, porteros, y un llamado archivo cada seccion sobre el consejo general. $=$ Todo este ejército no hizo nunca mucho, y no hacia casi nada últimamente. El 
La propia prensa reclamaba su reinstauración, pues de él dependía la renovación del Poder Judicial ${ }^{108}$. En este sentido, resulta elocuente la siguiente publicación del diario El Castellano, periódico de politica, administración y comercio:

“¿Cuántos consejos pueden existir legalmente en España? Según la Constitucion en artículo terminante solo el de Estado. - ¿Y este se halla establecido? No, ni ahora puede ser; porque las Córtes que hacen las propuestas por ternas no están reunidas. ¿Luego hasta organizarlo allá por S. Andrés, ó por Navidad, si Dios quiere, no se proveerán los planes de jueces ni magistrados? (...)"109

La respuesta del Ejecutivo fue crear una junta nombrada por el propio Gobierno encargada de "proporcionar á vuestro gobierno noticias, datos y conocimientos escatos que faciliten á su tiempo la completa organización de los tribunales y juzgados del reino"110. Se incumplía, de esta manera, la separación de poderes establecida por el texto constitucional gaditano, con los perjuicios que esto podia conllevar dado que, como se manifestaba por el rotativo Eco del comercio, “(...) habiéndose de nombrar los individuos de la junta exclusivamente por el gobierno, los nombrados no ofrecerán aquella garantía de independencia que tenían los consejeros de estado por ser su elección á propuesta de las cortes y por su carácter de inamovilidad (...)"111.

En seguida se sintió la necesidad de adaptar la Carta Magna a las circunstancias del momento. Para lograr este objetivo, se convocaron Cortes constituyentes, de las que resultó la Constitución de 1837. En esta no se recogió referencia alguna a la señalada Institución y tampoco fue prevista por el Proyecto Constitucional presentado por la Comisión ${ }^{112}$, pues no la consideraba como un poder constitucional ${ }^{113}$.

Sin embargo, si hubo discusión acerca de la conveniencia de su establecimiento. La misma tuvo lugar el día 17 de mayo de 1837, a propósito de la sugerencia de Gorosarri para que se añadiese el correspondiente título relativo al Consejo de Estado ${ }^{114}$. En defensa de esta propuesta habló Fuente Herrero, quien entendia que la existencia de un Cuerpo consultivo vitalicio que actuase

presupuesto era crecido; por consiguiente ha sido grande el servicio que se ha hecho á la nacion suprimiéndole. (...)", Eco del comercio, madrid, nº. 885, sábado, 1 de octubre de 1836.

108 Recordemos que la Constitución de 1812 le atribuía la potestad de proveer las plazas de judicatura.

109 El Castellano, Periódico de Política, Administración y Comercio, n 21, martes, 30 de agosto de 1836.

110 Exposición de motivos del de 22 de septiembre de 1836, Gaceta de Madrid, Núm. 625, sábado, 24 de septiembre de 1836.

111 Eco del comercio, $n^{\circ} 880$, lunes, 26 de septiembre de 1836.

112 La Comisión se eligió el 5 de noviembre de 1836. La compusieron los diputados Argüelles, Ferrer, González, Olózaga y Sancho, DSC, 05.11.1836, n 18, pp. 133-134.

113 Así lo dice Fuente Herrero: "Los señores de la comision no la han creido tan útil, pero han manifestado que prescindian de la conveniencia ó no conveniencia de un Consejo de Estado, y que lo consideraban inadmisible porque creían que no es un poder constitucional", DSC, 17.05.1837, no 199, p. 3419.

114 DSC, 17.05.1837, $\mathrm{n}^{\circ} 199$, p. 3419. 
como freno a la prerrogativa real ${ }^{115}$, era una cuestión de gran importancia y de absoluta necesidad para evitar graves trastornos en la administración pública. Por eso manifestaba su desconcierto ante el hecho de que el máximo órgano consultivo no fuese contemplado en el marco fundamental116.

El propio Argüelles manifestó su opinión negativa a que la propia Constitución reconociese la existencia de un Consejo de Estado. Esto, decía, era equivalente a limitar el poder real y sería contrario a la teoría constitucional mantenida por la Comisión, que consistia en atenerse a fijar principios generales, dejando los aspectos procedimentales a normas ulteriores. Como ejemplo se refería a que la Carta Magna se había ceñido a manifestar que la potestad de hacer las leyes residía en las Cortes con el rey, absteniéndose de regular la forma en que debian desarrollar dicha potestad, pues esto debía hacerse por leyes o reglamentos posteriores. Contemplar constitucionalmente este aspecto, afirmaba, supondría restringir la facultad de las Cámaras legislativas ${ }^{117}$. Lo mismo ocurría con el Poder Ejecutivo. El texto constitucional tenía que limitarse a manifestar, simplemente, que la persona del monarca era sagrada e inviolable y que a él correspondía la conservación del orden público en lo interior y la seguridad del Estado en lo exterior. Cualquier cuestión que se extendiese de estos extremos quedaba excluida de ser regulada en la norma fundamental. Siendo esto así, no tenía sentido configurar a la máxima Institución consultiva como un órgano constitucional. De lo contrario se vería limitada la facultad que el Gobierno tenía de escoger sus propios consejeros $y$, por consiguiente, de seguir o no su

115 "El Consejo de Estado, en los términos que yo le presento, no hace más que limitar en cierta manera el Poder ejecutivo en beneficio de la causa pública cuando trate de separarse de las leyes y obrar en contra de la Nacion: es un limite por el cual puede hacer el bien y se le dificulta hacer el mal; es un límite al Poder Real, al Poder ejecutivo (...)” DSC, 17.05.1837, n 199, p. 3419.

116 "En cuanto á que no se considere esta institucion como un poder constitucional, no encuentro razon, filosófica y politicamente mirado, para que pueda excluirse de la Constitucion. (...) Es verdad que la comision ha prescindido de la conveniencia ó inconveniencia de que se establezca; pero que pueda ser conveniente, la comision no lo ha negado, y tengo presente que en la discusion se dijo que se hiciera una proposicion que podria ser admitida. ¿Y qué inconveniente hay en que se establezca en la Constitucion, cuando nunca pasará de ser una opinion de la comision el que no pueda considerarse como parte del poder constitucional el Consejo de Estado? El Consejo de Estado en los términos en que se propone, haciendo responsables á los consejeros, no puede menos de producir bienes, nunca males; por consecuencia, no encuentro inconveniente, sino más bien utilidad en su establecimiento", DSC, 17.05.1837, n 199, pp. 3419-3420.

117 “(...) La comision no ha entrado en el exámen de la utilidad ó superfluidad del Consejo de Estado; lo único que ha dicho es que no cree propio de una Constitucion, cuyo proyecto es ya conocido, el decir que haya un Consejo de Estado con este objeto, y ordenado y compuesto de esta ó de la otra manera; (...) contrayéndome á la doctrina, á los principios conformes con la teoría constitucional que la comision ha presentado en su proyecto de Constitucion, diré que lo que desea el Sr. Fuente Herrero seria en este caso una limitacion, una restriccion para el Poder Real. ¿Qué se dice en el proyecto hablando de la autoridad suprema? Que la potestad de hacer las leyes reside en las Córtes con el Rey; y entrando despues á tratar de éstas y de sus atribuciones, se ha abstenido la comision de decir cómo han de ejercer esta autoridad. Ha fijado solo el principio de que las Córtes, compuestas del modo que se establecerá, y elegidos los que las han de constituir segun fijará la ley electoral, formarán las leyes, y no dice más, ni puede ni debe decir otra cosa. Cuál sea el método, cuál sea el órden que hayan de observar los Cuerpos Colegisladores, ó sean, las Córtes, en la formacion de las leyes, se deja ó para reglamentos, ó para leyes subalternas", DSC, 17.05.1837, n ${ }^{\circ} 199$, p. 3420. 
dictamen. Se estaría confundiendo entonces, como en 1812 , lo que debía ser acta constitucional con las demás leyes secundarias ${ }^{118}$.

Finalmente, la Constitución de 1837 no incluyó referencia alguna al Consejo de Estado. Aunque, tal y como predijo Argüelles ${ }^{119}$, pronto se dejó sentir la necesidad de volver al sistema de un Cuerpo único y centralizador de las funciones consultivas ${ }^{120}$, no se logró hasta 1845. Habria que esperar hasta la llegada al poder del partido moderado para que se emprendiese la reforma administrativa y se estableciese un órgano colegiado destinado a asesorar al Gobierno en los asuntos más complejos. Lo que se llevó a cabo con la ley de 6 de julio de 1845, que regulaba la figura del "Consejo Real", siguiendo los principios ideológicos de liberalismo doctrinario ${ }^{121}$. Se trató, sin embargo, de una Institución muy distinta a la gaditana. A diferencia de ésta, e inspirada en el sistema establecido en Francia, asumió funciones contencioso-administrativas y gozó de una dispar configuración, al ser sus miembros amovibles y elegidos directamente por el monarca. En consecuencia, se puede afirmar que la Corporación instaurada en Cádiz agotó su ciclo en 1823.

En nuestra opinión, el hecho de que no se restableciera el Consejo gaditano se debió a la negativa concepción que en la doctrina administrativista de la época tenía sobre la Administración consultiva instalada en 1812. En este punto debemos destacar el gran giro que se produjo en el pensamiento de Argüelles ${ }^{122}$. De considerar al órgano consultivo como un ente constitucional y consustancial al régimen, encargado de "dar al Gobierno el carácter de estabilidad, prudencia y sistema que se requiere" ${ }^{123}$, pasó a afirmar, en 1837 , que no debía considerársele

118 “(...) limitándose así la facultad que el Gobierno del Rey tiene de buscar los consejeros que le parezcan, y de seguir ó no su dictámen, podria creerse relevado de la responsabilidad que ha de pesar sobre el mismo Gobierno, en la forma que se establecerá en la ley orgánica que se hará al efecto. Bajo este aspecto, me parece que el establecimiento de este Consejo no debe formar parte de la Constitucion. (...) ¿cómo habia de incurrir la comision en el error de confundir lo que debe ser meramente acta constitucional con las demás leyes secundarias? De ningun modo. (...)", DSC, 17.05.1837, $\mathrm{n}^{\circ} 199$, p. 3421

119 “(...) Puesto que el Rey y los Cuerpos Colegisladores tienen igualmente la iniciativa, no admite duda en que la Corona, antes que pase mucho tiempo, tendrá por sí que venir á las Córtes pidiendo el establecimiento de un Consejo á quien consultar, sea cualquiera su denominacion ó bien las mismas Córtes conociendo más adelante su necesidad lo propondrán, pues no de otra manera podrá llenar cumplidamente el Poder ejecutivo las atribuciones que le están concedidas. Entonces será cuando en el reglamento ó ley orgánica que se acuerde para el establecimiento y gobierno de aquella corporacion podrán tener lugar muchas de las ideas del Sr. Fuente Herrero", DSC, 17.05.1837, n ${ }^{\circ} 199$, p. 3422.

120 José $\mathrm{M}^{\mathrm{a}}$ Cordero Torres, El Consejo de Estado. Su trayectoria y perspectivas en España, op.cit., p. 87.

121 Los identifica José Antonio Pérez Juan en "Centralismo y descentralización. Organización y modelos territoriales en Alicante (1812-1874), Instituto Nacional de Administración Pública, Madrid, 2005 y "El Ministerio de Comercio, Instrucción y Obras Públicas (1847-1851), Instituto Nacional de Administración Pública, Madrid 2008. “(...) el modelo a implantar seguirá las notas de uniformidad, subordinación, responsabilidad y presencia de las autoridades de todos los grados”.

122 La causa de esta variación reside, de acuerdo con José Luis Comellas, en que muchos de los hombres más exaltados de las Cortes de Cádiz, y entre ellos Martínez de la Rosa, Argüelles o el conde de Toreno, se hicieron moderados en el período del trienio liberal; adoptando ya en 1836 una actitud abiertamente conservadora. José Luis Comellas, Los moderados en el poder, C.S.I.C. Escuela de Historia Moderna, Madrid, 1970.

123 Discurso Preliminar a la Constitución de 1812, op. cit., p. 93. 
un ente constitucional y que su contemplación en la Constitución produciría relevantes limitaciones en el libre ejercicio del Poder ejecutivo. De la misma forma, José de Posada Herrera afirmaba que la referida Institución no satisfizo el objeto al que estaba destinado en ninguna de las dos épocas en que estuvo vigente $^{124}$. Por su parte, Joaquin Francisco Pacheco en un artículo de febrero de 1839, publicado en la "Revista de Madrid"125 mantenía que, aunque en 1812 se habia adelantado seguramente al suprimir las antiguas Instituciones, ese progreso era vago, indeterminado, vacilante, incierto, sin el grado de fijeza que era necesario en las cosas gubernativas; y calificaba al órgano colegiado como una segunda Cámara por su composición aristocrática ${ }^{126}$. Además, criticaba la forma de elección de los consejeros y el carácter inamovible del cargo, entendiéndolos absolutamente ajenos de todo fundamento ${ }^{127}$; y sobre su poder y autoridad manifestaba que:

“(...) se extendia sin duda en anchas é importantes regiones; mas que á pesar de eso, estaba tambien en algunos puntos corta, limitada, escasa, absolutamente, dejando vacíos y sin comprender capítulos importantes de lo que ya se juzgaba necesariamente subordinado á la institucion. Bástenos citar como prueba la jurisdiccion contencioso-administrativa (...)"128

También expresó una opinión negativa el Marqués de Valgornera, quien describía al Consejo de Estado como "un panteon de ministros ó favoritos que caian de la gracia del Monarca" en el que estaba presente el sello de los antiguos hábitos y costumbres. ${ }^{129}$

124 “(...) se puede decir que en ninguna de las dos épocas satisfizo verdaderamente el objeto de su instituto, ni aun en ninguna de ellas llegó á completarse el número de personas que le componian", José de Posada Herrera, Lecciones de Administración, op. cit., p. 309.

125 Joaquín Francisco Pacheco, “Consejo de Estado" en José Gallostra y Frau, Colección bibliográfica de lo contencioso-administrativo, Madrid, 1882, pp. 79-100.

126 “(...) Representacion indudable de clases, concesion necesaria de privilegios, que unidas á la forzosa incompatibilidad entre estos destinos y la diputacion á Córtes, indicaban ya la tendencia á un segundo cuerpo político; tendencia que venia á confirmar el artículo 236 de la Constitucion, por el que estaba obligado el Monarca á oir á este Consejo en los negocios graves gubernativos, y señaladamente para dar ó negar la sancion á las leyes, declarar la guerra y hacer los tratados", Gallostra y Frau, Colección bibliográfica de lo contencioso-administrativo, op.cit., p. 81.

127 “(...) Basta pasar ligeramente la vista por lo que fué, para percibir que no nos equivocamos en este juicio. La composicion del cuerpo ya la hemos indicado, si bien nos falta añadir que el nombramiento se verificaba por el Rey, á propuesta en terna de las Córtes, y que la duracion de los cargos era vitalicia, á no mediar una causa justificada ante el Tribunal Supremo. Disposiciones una y otra, cuyos motivos podrán hallarse en algun sistema politico; pero que como propias de una institucion administrativa, son absolutamente ajenas de todo fundamento, de toda razon. ¿Cómo ha de defenderse para un cuerpo de esta última clase la propuesta en terna por las Córtes y el nombramiento obligado del Gobierno? ¿Cómo ha de concebirse la inamovilidad y la vitalidad, en elementos y agentes de la administracion del poder ejecutivo?", Gallostra y Frau, Colección bibliográfica de lo contencioso-administrativo, op.cit., p. 81-82.

128 Marqués de Valgornera, "Consejo de Estado” en José Gallostra y Frau, Colección bibliográfica de lo contencioso-administrativo, op.cit., p. 82.

129 “(...) En esta institucion, ni bien española, ni extranjera, ni antigua, ni moderna, se observa, y esto es notable, el sello de los envejecidos hábitos y costumbres á que pagan tributo aún sus adversarios más poderosos (...)",Gallostra y Frau, Colección bibliográfica de lo contenciosoadministrativo, op.cit., p. 107. 
Esta misma percepción se extrae de la opinión pública de la época. A modo de ejemplo, el diario Eco del Comercio decía del Consejo de Estado que "según la forma y atribuciones que se le dieron en la constitución, es el cuerpo mas inútil que se pudiera idear en la composición de un gobierno, cualquiera que sea su forma"130 y los redactores de El guardia nacional aseguraban que su restablecimiento conllevaría muchos perjuicios ${ }^{131}$. De esta misma opinión era el editor del periódico El nacional, que consideraba que, habiéndose asumido por el Consejo de gobierno las principales facultades del máximo Cuerpo consultivo, era innecesaria y antieconómica su reinstauración ${ }^{132}$.

A pesar de lo manifestado, la necesaria existencia de una Corporación que aconsejase a los ministros en la resolución de los negocios más arduos, no era cuestionada. Muy al contrario, la doctrina lo consideraba imprescindible para la buena marcha de la administración. Clara muestra de esta afirmación, viene constituida por lo sentenciado por José de Posada Herrera. Este notable jurista, justificaba que se trataba de un órgano indispensable porque los ministros no tenían el tiempo necesario para poder meditar con la calma requerida dicho tipo de cuestiones $^{133}$. Además, entendia que, dada la temporalidad de estos cargos y su carácter político, si no existiese la referida Corporación, faltaría la necesaria unidad

130 Eco del comercio, n ${ }^{\circ}$ 936, lunes, 21 de noviembre de 1836.

131 "Un periódico de esta corte se ha propuesto seguramente convencer á los españoles, bajo un aparente celo de conveniencia pública, de la necesidad que hay de establecer el consejo de estado y quitar de un modo indirecto la regencia del reino á la augusta Reina Gobernadora, que tan dignamente la desempeña, y que tantos titulos tiene de que se la conserve en el puesto que ocupa.= El promover en dias aciagos, como los que esperimentamos, esta clase de contiendas, es á nuestro entender perjudicialisimo á la causa de la libertad que defendemos; y no sera nada estraño que aparentando muchos un celo falso por el bien de los pueblos, á imitacion de los Regatos y otros traidores de la causa de la libertad, sean pagados por manos estrangeras para promover esta y otras cuestiones, que no pueden tener otro objeto que el dividirnos mas y mas y envolvernos en mayores horrores de los que desgraciadamente esperimentamos. Afortunadamente la parte sensata de la nacion va ya conociendo de la falsedad de muchos que se titulan sus defensores, para no dejarse engañar de pomposas y bellas teorias.(...)", El guardia nacional, eco de la razon, $\mathrm{n}^{\circ}$ 330, sábado, 29 de octubre de 1836.

132 "Despues del cuidado de acabar la guerra civil, el primero que debe ocupar al gobierno debe ser el de hacer economias, ya rebajando los sueldos de los altos empleados, ya eliminando de la administracion aquellos establecimientos que el curso de los sucesos hace inútiles ó innecesarios. Asi esperamos que en atencion á que el Consejo de gobierno establecido por el testamento del Rey difunto tiene todas las facultades y prerogativas que gozaba el Consejo de estado que establece la Constitucion del año 12 que se acaba de proclamar, él lo declarará asi que este se entienda incluido en aquel, lo que proporcionará al erario una economía de mas de dos millones de reales, y ademas caducada la institucion del Consejo Real creado por el ministerio Martinez de la Rosa, cuya supresion, contando con lo que por clasificacion corresponderá á los individuos de esta magistratura, dará tambien otra economia de mas de un millon de reales.= Este sistema de economías tan inútilmente esperado de los poueblos facilitará al gobierno mas apoyo, fuerza y crédito entre los gobernantes, que cuanto pueda conseguir por cualquier otro rumbo.", El nacional, diario de la tarde, $\mathrm{n}^{\circ} 196$, domingo, 21 de agosto de 1836.

133 "No es solo necesaria la creacion de un consejo de estado, para que aconseje á los ministros en la resolucion de los negocios árduos y graves, de los cuales no pueden enterarse por sí detenidamente, y meditarlos en la calma que de suyo exijen, sino que es necesaria tambien para dar unidad y enlace á la administracion, á fin de que en todas sus disposiciones generales se siga un mismo principio y sistema. La misma variabilidad en el personal de los ministros, que es la indole de los gobiernos representantivos, hace necesrio, indispensable, un consejo de estado que se encargue de ciertos asuntos (...)", José de Posada Herrera, Lecciones de Administración, op. cit., p. 293. 
que debía presidir en la marcha administrativa de un ramo particular y también la armonía entre los diferentes Ministerios ${ }^{134}$ La Institución que se instaurase debía, según este autor, fuertemente influenciado por la doctrina francesa, reunir en su seno competencias consultivas y contencioso-administrativas. Y esto porque era absolutamente indispensable la configuración de una administración independiente y fuerte, capaz de enfrentar a los obstáculos que pudiesen interrumpir su marcha ${ }^{135}$. Se trata, a nuestro entender, de una muestra de la admiración por lo francés y del cierto complejo de inferioridad que reinaba en la época ${ }^{136}$. De esta forma, mientras el Consejo de Estado gaditano se entendía imperfecto e improductivo, se aspiraba a establecer un modelo inspirado en el país vecino.

\section{CONCLUSIONES.}

El primer Consejo de Estado constitucional fue instalado por decisión unánime de las Cortes en 1812. Los diputados gaditanos lo consideraban consustancial al régimen que se trataba implantar, pues veían en él un mecanismo de control sobre el Poder Ejecutivo y una herramienta indispensable para poder poner fin a la arbitrariedad existente hasta el momento. Tal era la importancia dada a este órgano, que los parlamentarios no quisieron esperar, ni a la promulgación de la Carta Magna, ni al retorno de Fernando VII, para proceder a su establecimiento. No fue necesario, siquiera, debate parlamentario acerca de la conveniencia de incluirlo dentro del organigrama administrativo. Si bien, no quiere esto decir que determinados aspectos relacionados con el mismo, como su configuración y competencias, estuvieran exentos de discusión.

Una de las cuestiones más controvertidas fue la relativa al número de consejeros, que finalmente quedó fijado en cuarenta. Parte de la Cámara entendía que dicha cifra debía ser reducida por motivos de carácter económico. Opinaban también que una Institución tan multitudinaria supondría un obstáculo a la energía con que debía obrar el Gobierno, o, incluso, que las facultades que se habian atribuido al Cuerpo consultivo podian ser llenadas sin dificultad por menos individuos. La mayoría de la Asamblea, no obstante, estuvo de acuerdo con el parecer de la Comisión, según el cual la composición que se había otorgado a la referida Corporación era la más idónea pues, de un lado, estaba destinada a actuar de correctivo ante la posible "impetuosidad" de la Asamblea legislativa, y, por otra parte, el gran número de negocios que se someterían a su conocimiento implicaria la necesidad de dividirlo en distintas secciones.

134 “(...) elevadas las personas al ministerio, generalmente mas bien por consecuencia de una opinión política que de sus teorías administrativas, varía, sin embargo, la manera de ver los ministros en las cuestiones que les estan encargadas (...) resolviendo cada uno segun sus ideas y segun su modo de ver particular, hay una variacion extraordinaria en las decisiones de los diferentes ramos de la administracion que desacredita las leyes y causa grandes perjuicios a los particulares (...)",José de Posada Herrera, Lecciones de Administración, op. cit., pp. 293-294.

135 “(...) son infinitas las cuestiones que se presentan en la administracion y que solo debiera resolver el consejo de estado, porque de lo contrario se seguirian males inmensos al pais. Si por ejemplo, en circunstancias azarosas, en la época de una guerra cree el gobierno conveniente fortificar un sitio dado y para esto necesita echar mano de terrenos particulares y estos se oponen á que la fortificacion se haga ¿habrá de sujetarse el gobierno á un litijio, seguido ante un tribunal de justicia, esponiendo la defensa del territorio y la causa general de todo el pais? (...)",José de Posada Herrera, Lecciones de Administración, op. cit., p. 294.

136 José Luis Comellas, Isabel II. Una reina y un reinado, Ariel S.A., Barcelona, p. 183. 
Tampoco fue pacífica la idea de que dichos cargos fuesen inamovibles. Los que se opusieron a ella, alegaban que la perpetuidad de estos destinos solo facilitaría el incumplimiento de sus deberes; mientras que los favorables a la misma manifestaban que la seguridad que en sus componentes produciria la estabilidad en sus puestos y derivaria en un mayor interés en el ejercicio de su labor.

Otro punto de discordia vino constituido por las competencias que debian atribuirse al Consejo de Estado. Muchos consideraron que el artículo 235 era demasiado indefinido, y requerían una mayor concreción de las facultades que debian atribuírsele. Mantenian que, si no se especificaban las mismas, quedaria a la voluntad del monarca o, lo que era peor, de los ministros, su fijación, y esto no podría derivar más que en su inactividad. Sin embargo, fue más fuerte el miedo de los parlamentarios a coartar las facultades del monarca y entorpecer su enérgica acción, pues el precepto se mantuvo en los términos marcados por la Comisión.

En nuestra opinión la indiscutible importancia que en 1812 se daría a este órgano consultivo se encuentra directamente vinculada a la inexistencia de una Cámara alta en las Cortes. En este sentido, es fácilmente apreciable cómo, además de entenderse como un arma del Parlamento para controlar los actos del Gobierno, primó su consideración de ente conciliador, intermediario entre los Poderes Ejecutivo y Legislativo. El período absolutista no cambió esta percepción. Una vez restablecida la Constitución en 1820, se reinstauró también la Corporación consultiva. No existió, de nuevo, quien cuestionase la idea de que se trataba de una Institución esencial de la Administración pública. Muy al contrario de la lectura de los debates parlamentarios y de la prensa de la época, se aprecia su exaltación, llegando a ser calificada como "timón de la nave del gobierno" o "sostén del sistema constitucional y de la libertad nacional".

Sin embargo, la década ominosa y el exilio de algunos de los más relevantes representantes de la nación, sí cambiaron de forma radical la imagen de órgano constitucional indispensable que, hasta 1823, se tuvo del máximo ente consultivo. La intervención de Agustín Argüelles en las sesiones parlamentarias de 1837 es una clara muestra de esta mudanza. De ser considerada como una Corporación que, por ser imprescindible, debía estar contemplada en la Constitución, pasó a ser relegada a un segundo plano, siendo entendida como materia que debía regularse en una norma ordinaria. No hay que olvidar, en este sentido, que el texto constitucional de 1837 sí que preveía la existencia de un Senado, por lo que el referido Cuerpo consultivo ya no devenía en indispensable. Su ausencia, de hecho, se consideró como beneficiosa para la resentida economia del país.

Es clara, por tanto, la notable pérdida de reconocimiento que sufrió el Consejo de Estado en algo más de una década. Más aún si se observa la percepción que del mismo tenía la doctrina contemporánea $\mathrm{y}$, en concreto, el pensamiento de José de Posada Herrera, que lo acusaba de no haber cumplido nunca su objetivo; o Joaquín Francisco Pacheco, que lo consideraba una segunda Cámara por su composición aristocrática.

Fecha de envío / Submission date: 25/01/2017

Fecha de aceptación /Acceptance date: 14/04/2018 